\title{
Textes de création
}

\section{Génèse : Du dedans et du dehors : un socle commun Sylvie FRIGON et Sophie COUSINEAU, Université d'Ottawa}

Du dedans et du dehors... cette expression inscrite dans l'actualité (événements, manifestations, symposiums) se réfère aux initiatives culturelles menées en prison et aux productions carcérales diffusées en société. Ce rapport itératif est d'autant plus marqué par une altérité : changement des perceptions, redéfinition des personnes impliquées, transmission de connaissances, etc.

Qu'il soit question de pièces de théâtre représentées par les détenus de William Head en Colombie-Britannique, de formation à la création visuelle et sonore au Centre pénitentiaire de Marseille-Les Baumettes, de chorégraphies faites par les ex-détenus du pénitencier de Sing Sing, d'Agir par l'imaginaire, un projet d'ateliers et d'exposition artistique marrainé par Engrenage Noir LEVIER et la Société Élizabeth Fry du Québec, l'art devient une courroie de transmission pour relier ces deux sphères. L'art concilie des logiques antinomiques au premier abord: sécurité et contraintes versus liberté et expressivité. L'art fait enfin naître des collaborations humaines.

Dans cette même mouvance, les enjeux carcéraux sont abordés par divers médiums de représentation. L'univers des femmes incarcérées n'est pas épargné avec la diffusion d'Unité 9 depuis septembre 2012 à la Société Radio-Canada et d'Orange Is The New Black sur les ondes de Netflix depuis juillet 2013.

Par ailleurs, la Chaire de recherche de professeure Sylvie Frigon La prison dans la culture, la culture dans la prison et le projet collaboratif avec l'AAOF (Association des auteures et des auteurs de l'Ontario français) s'inscrivent dans ce double mouvement. Cette initiative de Jean Malavoy actualisée par le président de l'AAFO Yves Turbide et dirigée par Sylvie Frigon, s'est soldée par des ateliers en milieu carcéral et communautaire. L'Établissement Leclerc pour hommes à Laval, le pénitencier pour femmes de Joliette, le Centre de détention à Marseilles, le Centre Élizabeth Fry de l'Outaouais, La rue des Femmes et Les Impatients constituent les lieux où se sont tenues ces rencontres littéraires. En amont, il y a eu un atelier-spectacle de slam avec l'artiste Louise Poirier, Valérie Descroisselles-Savoie et les femmes du Centre Élizabeth Fry de de l'Outaouais à l'automne 2010.

Cette fois, Sylvie Frigon ainsi que Tina Charlebois, Éric Charlebois, Guy Thibodeau, Lise Careau, Alberte Villeneuve-Sinclair, Michèle Vinet et Martine Bisson Rodriguez, membres de l'AAOF, animés par une démarche pédagogique de leur crû, pénètrent ces lieux dès l'automne 2011 et donnent une voix aux participants enfermés. Bien sûr, il y a la détention physique à proprement parler, mais aussi l'enfermementstigmate, l'enfermement-émotion ou l'enfermement-supervision. Nous y reviendrons plus tard.

Dans l'un comme dans l'autre de ces états, la fiction devient un vecteur qui rend l'imaginaire fécond et qui facilite la mise en récit. Par ailleurs, aucun sujet n'est imposé, aucun tabou n'existe : la plume devient une liberté d'occasion pour les participants encarcanés. Ainsi, la rencontre littéraire entre l'écrivain et le participant génère apprentissages, échanges et transformations. Les premiers sont marqués par l'expérience carcérale, ses contraintes et l'échange-citoyen qui s'y déroule. Les seconds s'outillent, s'explorent et se découvrent. Partout, la rencontre littéraire ne laisse personne indifférent. 
Ce projet possédait trois objectifs : donner une voix aux personnes incarcérées, à celles ayant vécu la judiciarisation ou l'institutionnalisation ; permettre un échange du dedans et du dehors via l'écriture ; publier les textes des participants côte-à-côte avec les auteurs-animateurs et les artistes. La parution d'une part de ces œuvres dans Voix Plurielles poursuit donc ce troisième point et agit comme un tremplin pour les voix du dedans.

Somme toute, la majorité des textes réalisés sont issus des ateliers collaboratifs. Dans un premier temps, ce sont ceux des auteurs-animateurs et des participants. Dans un deuxième temps, ce sont les productions artistiques des gens du dehors. Ces fragments partagent néanmoins un socle commun : la rencontre dedans/dehors.

\title{
Les lieux
}

A-L'Établissement de Joliette, l'un des cinq pénitenciers pour femmes au Canada, accueille les détenues devant purger une sentence supérieure à deux ans. Avec une capacité de cent quinze détenues, cet établissement à sécurité multiple comprend un secteur maximum (milieu de garde fermé), un milieu de vie structuré et des unités résidentielles de vie (niveau medium et minimum). Une nouvelle unité de vie est prévue pour 2014.

http://www.csc-scc.gc.ca/etablissements/001002-2006-fra.shtml

\section{Michèle Vinet @ Joliette}

QUUVES DES AUTEURS-PARTICIPANTS

\author{
INCLINAISON (France) \\ Rivière \\ Oxygène \\ Paix insubmersible \\ Fraîcheur nouvelle \\ Ambulante \\ D'une amitié \\ Naissante \\ Libertine \\ Convenable \\ Riche d'émotions \\ Sans mots \\ Pleins de sens
}

VRAI ET FAUX (France)

Jugement Non Coupable

Absence voulue

Solitude bienvenue

Sourire radieux

Larme sèche 
Amour compris

Vie remplie

Temps passant

Famille unie

Porte ouverte

Vie inchangée

FLEURS (France)

Ces fleurs

Fanées

Dans un coin

Pénitence

Ces fleurs bleues

De pleurs

Désillusionnés

Versés

D'un cœur

Intentionné

SANS TITRE (Sonya)

Aventure

Trépidante

D'une vie

Ravagée

Reconstruite

Retrouvailles

Amoureuses

Blessure

Soignée

Le cœur

Guéri

Éternité

De soif

D'ignorance

Tourmentée

Savoir

Rechercher

La vérité

Limpide

Éclatante

Splendeur

De la vie

Gloire 


\section{Du repos}

Paix

Essentielle

Calme

De l'esprit

Dévasté

PÉRIPLE (Liz)

Femme en croisière

Au cœur de l'été

En vacances

Flâne

Au bruit des vagues

Humant l'air

Jouissance

Du calme

D'évasion

Tangue

Au rythme des oiseaux

Et de la faune marine

MYSTÈRE (Liz)

À l'aurore

Oasis de paix

Au bruissement des feuilles

J'entends

Le son velouté des cigales

Émergeant je ne sais d'où

Maison délabrée

vieillotte

Remplie de mystère

Croupi au milieu

Jardin de fleur

Reflétant

Un secret certain

Le goût

D'y percer

Le mystère

APPRENTISSAGE (Liz)

Parents émerveillés

Fous de leur progéniture

$\mathrm{Ne}$ voient que du feu 
Simples défricheurs

Amoureux de la vie

Ouvrant leurs bras cajoleurs

Un poupon à ses premiers balbutiements

En attente d'affection

Bagage de confiance et d'amour

Bébé palpitant de joie

Au sein du jardin potager

Dans un décor harmonieux

Un paysage verdoyant

De jeunesse en effervescence

Générant un rayon de soleil

Blotti au cœur d'un gîte

Une richesse une beauté

Avec l'allégresse pour

Applaudir ce doux moment

Qui mènera la lancera pour

Voler de ses propres ailes

Baignant de simplicité

Seule au monde

Famille réunie

Explosant de joie dépareillée

Guide son aînée vers l'aventure

Sans oublier la douleur de l'apprentissage

Rejoindre les bras tendus

Au risque de chute

Y parvenir pleine d'amour

Suivre une route fleurie de confiance

Émanée de cette démarche innocente

SANS TITRE (Sonya)

Des fleurs

Une grange

À la tombée du jour

Où sont réunies

La vie

La joie

La douceur

L'excitation qui n'en finit plus

Le mystère

L'euphorie

Hallucinogène

Pour les yeux 


\author{
Vivante \\ Merveilleuse \\ Déploiement des couleurs \\ Explosion des odeurs \\ Insécurité douteuse \\ Enchantement du rêve éveillé \\ Solitude envoûtante \\ Étrange paradis \\ Multicolore \\ Réel ou irréel \\ Paisible sensation \\ D'un jardin secret \\ De papillons \\ Un amant \\ Une cigarette à la main \\ Un tatouage \\ Sur l'épaule \\ Le jour se lève \\ Dans la froideur \\ Un bateau au loin \\ Une machine à tatouer \\ L'air misérable \\ Réveillé \\ Dur \\ Odeurs de fumée \\ Dans la frustration \\ Tant de répétition \\ Une amoureuse secrète \\ L'emprisonnement \\ Artificiel \\ Époustouflant \\ Dans son coin de cellule
}

\title{
1. Sans titre (Ciel)
}

Ancêtre

Sagesse

Richesse

Intelligence

La paix

Les oiseaux de nuit

Le vent dans les feuilles

La connaissance

La gratitude

L'air pur

L'air frais 


\section{L'atmosphère tranquille \\ Relaxante \\ Reposante \\ Coucher}

2. Sans titre (Ciel)

Solitude

Tranquillité

Équilibre

Responsabilité

Fatigue

Douceur

Flottement dans l'après-midi

Inconnue

Île au trésor

Lumière toute douce

Saine et sauve

Monde magique

3. Sans titre (Ciel)

Aventure sans fin

Nuages

Vol

Pays chauds

Voyage

dans l'éternité sans larmes

Esprit libre

Traverser

l'infinité

AVENTURE (Liz)

Une aventure

De fin de vie

Remplie d'émotions

Difficiles à digérer

En milieu fermé

Évasion barbelée

Brin d'espoir

Horizon bleuté

Voyage rêvé

Chemin de liberté

Bâtir à nouveau

Redevenir Zen 


\section{L'ANGE DE LA LUMIÈRE (Sonya)}

Alexane, une jeune mère rayonnante de bonheur à l'allure d'un ange, vêtue d'une grande cape blanche. Cette femme, illuminée de force et de courage malgré son cour ravagé par la souffrance et la douleur intense, déchirée par la perte immense et inconsolable de l'être aimé. Si forte et si fragile à la fois.

Elle porte son enfant, son amour minuscule, mais grandiose, son fils bien-aimé, l'enfant tant attendu d'une famille autrefois unie. Elle porte son petit William magnifique. Ce cadeau de la vie, sa raison de vivre. Elle le porte, attaché à elle par un vieux drap en forme de bandoulière. De là, elle le surveille d'un regard rempli de passion, d'amour et d'admiration. Elle ne peut s'empêcher d'avoir au plus profond de ce regard, cette peur bleue et froide comme les ténèbres d'un glacier. Cette peur terrifiante de le perdre lui aussi.

Derrière cette force inébranlable qu'elle puise dans le souvenir de son mari, son tendre amour, celui qu'elle s'est promis d'aimer pour toujours et que la guerre lui a sauvagement arraché, se cache une femme démunie et perdue, sans abri, sans l'amour et la chaleur des bras enveloppants de son homme, sans père fort et aimant pour son fils, sans protecteur pour eux.

Malgré tout, elle refuse de se laisser aller dans un tourbillon de désespoir. Si ce n'est pas ici, ce sera ailleurs. Mais ils trouveront un endroit où ils pourront se reconstruire, loin de la pauvreté et de l'artifice, dans la simplicité et la liberté, car ils ont la plus grande richesse du monde, l'amour et la complicité.

Alexane et William, tous deux éperdus de l'être aimé, savent qu'il est et sera toujours présent dans leurs souvenirs, leurs pensées les plus folles et les plus merveilleuses et ils sont profondément convaincus qu'il les guide.

Maintenant, ils sont en paix et en sécurité, car ils ont un ange gardien et ils le retrouveront un jour.

\section{UNE DISTANCE EXASPÉRANTE (Foxy)}

Sans toi, ma vie bascule

Assise au fond de ma cellule

Je sens une chaleur

Est-ce toi qui m'envoies cette douleur

La distance de notre amour

Est de plus en plus lourde

Pourrons-nous un jour être heureux

Dans ce monde de malheureux

Toi l'homme de ma vie

Seras-tu enfin plus qu'une rêverie

LA FENÊTRE OBSCURE (Foxy)

Je regarde par la fenêtre de ma cellule

Et je vois ces femmes condamnées

Je ne peux que souffrir

Lorsque je vois cette douleur les envahir 
Pourquoi ces dames sont-elles insupportables

Je ne peux demeurer dans ce monde de cruauté

THE MAN OF MY LIFE (Foxy)

Le soleil se lève

Je ne sens plus tes lèvres

Je ne sais plus quoi faire

J'aimerais sentir ta chair

$\mathrm{Tu}$ es mon seul manque

Je voudrais m'accrocher à ton ancre

Le jour où je vais me lever

Et que tu seras à mes côtés

Je vais enfin pouvoir te dire :

Je t'aime mon chéri

LA CELLULE DU DEUIL (Foxy)

Le soir, couchée dans ma cellule

Je regarde ta photo et je me dis

Que j'aimerais revenir en arrière

Le soir, couchée dans ma cellule

Je pense à toi couché près de moi

Et ces murs de béton me découragent

Le soir, couchée dans ma cellule

Je ne pense qu'à toi

Et plus rien ne nous sépare

\section{LE TEMPS IMPÉNÉTRABLE (Foxy)}

Le temps passe mais tu n'es pas là

Tu n'es pas là pour me prendre dans tes bras

Mes moments de souffrance

Je voudrais les vivre en ta présence

Toi l'homme que je désire tant

Pourrais-tu un instant

M'enlever cette souffrance

Aventure

De l'au-delà

Perdu

Sans crainte 


\section{Retrouver \\ Cette étincelle \\ Cachée \\ $\mathrm{Au}$ fond de lui}

\section{CABELLO (France)}

Aujourd'hui, je vis, mon rêve d'enfance enjolive ma vie. De ses seize mains de hauteur, Cabello se fait mon chevalier du moyen âge. Athlétique, vaillant, complice, d'un noir d'ébène, je suis sienne, il est mien. Mon frisson de six ans s'impatiente. Je l'entends au loin, il me parle, il hennit, il piaffe. Je sais très bien ce qu'il veut. Son ventre crie, je suis en retard ce matin. Il ne peut comprendre que mon sommeil n'était pas au rendez-vous cette nuit. De mauvais rêves me harcelaient et m'ont enfin quittée à l'aube. J'arrive, Cabello, j’arrive.

J'entre dans son château, l'odeur de la paille fraîche enivre mes narines, je me sens chez moi, chez lui. Quel bonheur ! Mon étalon m'épie attentivement pendant que je prépare son festin de mil et d'avoine, il raffole habituellement de ce mélange, mais ce matin, il lève le museau sur sa gamelle. Je suis perplexe et il piaffe de plus belle. Peut-être a-t-il besoin de sa liberté journalière ? J'ouvre donc le loquet de l'écurie. Il s'élance, fougueux, presque à l'épouvante dans le champ couleur maïs. Il galope de long en large, s'arrête et se balance comme un ours en colère. Il sent l'imprévisible qui arrive.

Des ombres couvrent le ciel, des formes gigantesques. De grandes ailes s'étalent audessus de lui. Ces créatures étranges l'imprègnent et le couvrent complètement de leurs ailes veloutées et majestueuses. Cabello se démène avec toute la fougue que seul un étalon sait montrer. Je suis là, sans broncher. Je devrais ameuter le village, mais mes muscles se figent. J'assiste à cette scène comme une statue de pierre.

Sérénité soudaine ! Même les oiseaux se taisent. Mais que fais-tu, Cabello ? Bats-toi ! Son regard maintenant séraphique croise le mien. Il me fait comprendre qu'il doit partir. Enveloppé d'une aura subtile, dégageant un parfum de paix. Je ne peux qu'acquiescer à sa demande. D'un geste gracieux, il étend ses nouvelles ailes énigmatiques et s'élève gracieusement au-dessus de ma tête. Je pleure en moi. Il disparaît suivant son chef Pégase. Il s'envole vers son destin, la où le monde n'existe pas, pas comme on le connaît.

Je suis vide, perdue et seule. J'entends soudain du bruit qui vient de l'écurie. Le hennissement d'un poulain... De son poulain.

\section{ANS. . . (Liz)}

Vie professionnelle très remplie

À l'aube d'une retraite bien méritée

Saga dépassant l'entendement

Rêvant de voyages et de farandoles

Aboutir sous les feux de la rampe judiciaire 
Réveil, réalité brutale

Tout pour chambouler l'être

Valse carcérale non rythmée

Méandres d'un procès

Fortement médiatisé

Apprentissage douloureux

Jungle de misère humaine

Un jour à la fois pour y survivre

Trimbalée de Centre en Centre

Diversité culturelle opprimante

Amour-propre en péril

Dédales de mesquineries

Délimiter son territoire

Écorcher à l'occasion

Quelques sensibleries

Cocasses et cruelles

Journées amochées

Intervenants chevronnés

Ayant à cœur notre rémission

Si suffocante d'émotion

Piaule pour s'y réfugier

Visite pour se revigorer

Sortie pour se ressourcer

Chemin de transition

Arriver à bon port

Retrouvailles de la liberté

Tant soupirer

Devenir plus zen

Oublier les péripéties

Introspection

Laps de temps

Perdu ou vécu

RETROUVAILLES (Sonya)

Un havre de paix si parfait

Au crépuscule

Dans l'harmonie de la nature

Qui se bouscule

Cette eau divine

Et cette douce bruine

Que la rivière berce

Dans son torrent 
Vivifiant

Un parfum de fraîcheur

D'une couleur ombragée

Par la nuance des rochers

Puissants

Et enveloppants

La joie qui coule

Renaissance

Et liberté

La force imposante

D'une chute dans la pénombre

Une famille au passé sombre

À ses côtés

Un arbre

Majestueux

Orange et solide

Veille sur elle

Unification de la vie

MON AMOUR (Sonya)

Quand je te regarde dans les yeux

Je vois une douce lumière

Toi tu es là

Derrière

Reflet de ton âme

Prison de tes mots

Une larme sur ta joue

Je te regarde

$\mathrm{Tu}$ es si beau

$\mathrm{Tu}$ veux dire quelque chose

Tu restes muet

Je veux lire en toi

Entendre ta voix

Autrefois ce silence me charmait

Aujourd'hui il m'effraie

Pourquoi as-tu si peur

Peur de toi

Peur de moi

Peur de tes vibrations

De tes émotions

Tu dois me dire tes pensées

Pour qu'entre nous

L'amour puisse durer 
Laisse tomber ton armure

Je sais que ton cœur est pur

Avec toi je veux tout partager

Ta douleur ton bonheur

Ta tristesse ta sagesse

Entendre l'écho de ton cœur

Le refrain de ton amour

Montre-moi qui tu es

Jamais au grand jamais

Je ne me moquerai

De toi et de ta vérité

Jamais je n'oserai te blesser

Car je t'aime

Je t'aime d'un amour

Profond comme l'océan

Plus fort aussi

Que son torrent

JARDIN SECRET (Liz)

Patelin paisible

Calme matutinal

Un homme déambule

Muni d'une valise vieillotte

Rituel quotidien

Bravant les intempéries

Intrigue à la fenêtre

Démarche chancelante

Échine courbée

Empreint de mystère

Itinéraire sans détour

Consacre son destin

Accompagné de Pato

Son ami épagneul

Un écho au loin

Attirance inconditionnelle

Y puiser son énergie

Y étaler son état d'âme

Se farcir d'amour

Auprès d'une épaule

Largement sollicitée 
Arrive à bon port

Déverrouille son intimité

Déplie ses lettres parfumées

Encense ce moment privilégié

Pato s'accroupit

Respecte le protocole

Ce matin pluvieux

Camouflé sous son imper

Un voisin bien intentionné

Démystifie le scénario

Se sent penaud

Intrusion édifiante

À travers le dédale

Des pierres tombales

Découvre feue Mme Untelle

Disparue 2 ans déjà

Savoure l'idylle vivante

Susurrée par cette âme-aimante

Gestuelle de la main

Embrasse sa dulcinée

Lui souhaite - Bon repos -

Hume les effluves odoriférants

Retourne vers son écritoire

Ravitaille cette valise d'antan

Cousue de poèmes inépuisables

Au menu du prochain récital

SOLITUDE (Liz)

Brume et brouillard

Mer écumée

Banc en attente de confidences

Reçoit Séraphine

Femme amère dans la quarantaine

$\mathrm{S}$ 'isole, tente de se détendre

Scrute l'horizon

Laisse libre cours à ses humeurs

Analyse ses angoisses

Se remémore son vécu

Divague sur sa jeunesse

Se rebiffe en son for intérieur 
Enfance négligée

Misère, solitude

Contrecoups accumulés

Berce ses illusions

Ombre à l'improviste

Dissipe ses lubies

Une inconnue s'invite

Rompt le silence

Entame des bribes décousues

Méandres de son passé

Rassérénés au présent

Se sourire

Commenter les flots

Verbaliser ses valeurs

Stratégies du mieux-être

Fusion de deux solitudes

Séraphine et Delphine

Tissage de liens

Échange de coordonnées

Solitudes cicatrisées

Promesse de retour

Au banc apprivoisé

\section{RÊVE-RÉALITÉ (Liz)}

Gambade, sur une route parfumée

Benjamine, coiffée de ses huit ans

Revient d'une journée d'apprentissage

Rêvant d'étreindre sa Maman

Pour épancher son baluchon d'émotions

Se heurte à un vide fragile

Entrevoir un livre-ami

Gisant sur le plancher verni

L'entrouvre, y fait son nid douillet

Recroquevillée sous sa couette

Voyage entre marée et vent

Juchée sur un cerf-volant

Autopropulsée vers une bulle ouatée 
Gonflée de douceurs

Épuisée de bonheur

Roupillon en sueur

Rêve à une fée merveilleuse

L'enveloppant dans une chaude étreinte

Surprise ! Maman est de retour

Réveil au baume enivrant

Bisous mon amie-Maman

Bisous mon ami-livre

DÉMARCHE DE SURVIE (Liz)

Naufragé sur une île déserte

Débrouillardise pour y survivre

Détenu en terrain barbelé

Cerveau en ébullition

Enjambé sur échasse

Fil de l'équilibriste

Outils d'Alcatraz

Cavale vers un mieux nanti

Un brin de folie déjà voué à l'échec

Rien d'un feu de Bengale

Donc...

Introspection expérimentale

Approfondissement du milieu

Logistique d'appoint

Agir au lieu d'ergoter sur des riens

Bouquinage versus broutilles

Bouder les ragots en catimini

Arc-en-ciel à l'horizon

Chemin de Compostelle

Bifurcation, tangente sobre

Tout apprentissage apprécié

Plein air tonifiant

Un jour à la fois

Porteur de petits bonheurs

Richesse de la surconscience

Retrouvailles des frangins

Ficelées d'espoir et d'estime de soi

Mettre de l'eau dans son vin

Comme la formule gagnan 
Avoir du panache

Sans vergogne vers la liberté

Vilain petit canard de la couvée

Devenir cygne aux ailes déployées

Plein feu sur la rampe

Joueur d'avant-scène

Cœur au gouvernail

À bon port. Bonne envolée !

Digne vécu ou peine perdue

Annalité bénéfique

\section{B-Établissement de Marseille}

Le Centre pénitentiaire pour femmes de Marseille (Les Baumettes) entre en fonction dès 1936 et est apte à recevoir 1373 personnes. Deux régimes de détention coexistent en son sein et il est constitué de quatre centres dont la maison d'arrêt pour hommes et le centre pénitentiaire pour femmes. 87 places sont disponibles pour ces dernières.

http://www.annuaires.justice.gouv.fr/etablissements-penitentiaires-10113/direction-

interregionale-de-marseille-10126/marseille-10796.html

\section{Sylvie Frigon @ Marseille}

Sylvie Frigon est titulaire de la Chaire de recherche La prison dans la culture, la culture dans la prison. Dans le cadre de celle-ci, elle a instigué ce projet de collaboration entre l'AAOF (Association des auteurs et auteures de l'Ontario français) et les établissements carcéraux et communautaires pour mettre sur pied des ateliers d'écriture, et éventuellement la publication d'un recueil collectif.

GUVRES DES AUTEURS-PARTICIPANTS

\section{Les contes}

\section{LA PETITE FILLE ET LE THÉÂTRE DE MARIONNETTES (Dorian)}

Il était une fois, une petite fille au doux prénom de Maya

Qui habitait le centre-ville de ROUEN.

Elle faisait partie d'une famille qui tenait un théâtre de marionnettes

Tous les jours à la sortie de l'école, Maya et ses deux autres sœurs se Précipitaient voir ses parents qui tenaient le théâtre, et entendre les jolies Contes de GRIMM, de PERRAULT comme le petit chaperon rouge Que ses parents à l'aide de marionnettes actionnaient et leur donnaient vie Tout d'un coup, un après midi, un vent violent se leva puis le simple vent se transforma en ouragan.

Les parents et les enfants, (tous les enfants car après l'école les enfants de tout âge venaient voir le spectacle) eurent tout juste le temps de se mettre à l'abri et virent le beau théâtre de marionnettes complètement détruit. 
Maya sanglota si fort que ses parents lui promirent à elle et à tous les enfants qu'ils reconstruiront un nouveau théâtre de marionnettes.

\section{LOUIS 2 ET LA TORNADE DE LA FORÊT (Zohra)}

Il était une fois Louis 2 de Bavière, un joli petit garçon âgé de 8 ans, descendant d'une famille richissime de nobles Allemand.

Il a les yeux bleus et de magnifiques petites boucles dorées.

Il vit dans un château avec son frère et sa petite sœur. Sa mère est décédée en mettant au monde sa petite sœur Madeleine qui a aujourd'hui 3 ans.

Toute cette merveilleuse famille vit donc entourée de nourrice, femme de ménage et tout le tra-la-la de la haute société, avec un père souvent absent.

Pas loin de sa demeure, il y a une grande forêt, où Omar, l'homme-à-tout-faire, lui a construit une magnifique cabane perchée dans un arbre si haut qu'il lui a rajouté une échelle en bois pour parvenir à cette cabane.

Louis dit Louis 2 de Bavière a pour habitude de se rendre dans cette forêt à chaque fois qu'il n'a pas d'école. Ca tombe bien, c'est les vacances scolaires et il a besoin de se retrouver seul dans cette cabane, certainement pour penser à sa mère qu'il a très peu connue.

Il demande l'autorisation à Mama Fatou, sa nourrice depuis toujours, qui accepte mais lui demande d'être rentré pour le repas.

Il s'en va à vélo mais prudemment car le temps est lourd, le ciel est gris et nuageux.

Même pas arrivé à sa cabane qu'il commence à pleuvoir.

Il pleut tellement fort qu'il décide de descendre de son vélo pour continuer à pied. Il monte dans sa cabane, il a froid et il est trempé.

Il enlève son petit gilet en col V et s'asseoit sur son matelas. Il avait mis en réserve des petites friandises qu'il dérobait dans sa maison.

Il pense, réfléchit, s'imagine dans le futur. Pense à sa pauvre petite maman qu'il a très peu connue.

Le temps passe tellement vite qu'il ne s'en rend pas compte.

Il veut rentrer mais il pleut encore plus fort que quand il est venu. Il se dit qu'il va attendre un petit peu.

Mais tout à coup, une immense tornade se lève. Il a peur, il est crispé, il ne bouge pas juste pour manger du chocolat, ça le rassure, ça lui fait du bien.

Il prie comme on lui a toujours appris dans sa famille catholique.

Ça se calme.

Dehors, tout est ravagé, détruit, écrasé et emporté.

Maman Fatou et Omar s'inquiètent pour Louis 2 Bavière. Ils s'en vont le chercher, Omar sait où il est. Ils marchent, marchent, Mama Fatou n'en peut plus mais ils arrivent enfin à la cabane.

Omar monte et trouve le petit Louis assis tranquillement. Tout calme, tout sage.

Ils redescendent alors tous les 2 et Louis tellement choqué de voir le paysage détruit qu'il ne se rend même pas compte que son vélo a disparu.

Mama Fatou est heureuse de le voir, elle le serre très fort dans ses bras.

Arrivés au château, tout le monde les attend avec impatience.

Son père tellement strict et froid court vers Louis et lui dit : "Mon fils je suis si heureux de te voir. J'ai eu si peur» 


\section{$\underline{\text { Lettres fictives }}$}

\section{LETTRE FICTIVE (V)}

Lettre à l'intime de moi-même. Je voudrais prendre enfin soin de toi. Te découvrir sans cette peur qui m'indigne, errer en tes travers et sourire de ton ventre. Je voudrais te connaître par la moelle et le sang, te respecter, respecter les larmes et cesser de les transformer en armes. Je voudrais rire de mon innocence quotidienne et de mes yeux révulsés pour que l'attente des jours pluvieux me fasse pousser des ailes. Je voudrais te prendre dans mes bras et t'aimer entièrement jour et nuit, rouge ou bleu. Avoir sans cesse le courage de t'aimer, te propulser dans l'air ou te rouler dans l'herbe. La terre est aussi ton domaine et je veux que tu y pousses intime de moi-même. Je t'aime, je t'aime, je t'aime, je t'aime, je t'aime, bon!

\section{LETTRE FICTIVE (Manora)}

$16 / 05 / 2012$

Cher Farid,

Je t'écris cette lettre pour te dire qu'en faisant du mal, tu gagnes le mal et ça ne te rapportera rien. Aujourd'hui, tu payes pour tout le mal que tu m'as fait et que tu as fait aux autres.

Tu as gaché toute ta jeunesse, tu ne fais que rentrer en prison, tu ne fais rien de bien. Tu ne fais que que te droguer, voler, frapper. Malgré le mal que tu m'as fait, je ne veux pas que tu rentres en prison.

Tôt ou tard, quand on fait le mal, on paye.

Je t'aime depuis longtemps, et tu ne veux pas sortir de mon cœur. Tu es le seul homme que j'ai eu et aucun homme ne peut faire en sorte que je t'oublie.

Je pense toujours à toi, aux bons petits moments qu'on a passés.

Je ne sais pas ce que tu m'as fait, mais tu m'as ensorcelée

Je t'ai toujours dit de te calmer. Ça sert à rien de rentrer en prison. Tu as la tête dure et tu es têtu.

Je t'ai maudit, mais au fond de moi, tu t'es foutu de ma gueule, tu m'as fait trop de mal, tu m'as brisé le cœur, je suis déçue, je n'ai plus confiance. A cause de toi, je me méfie des hommes et j'espère que c'est la dernière fois que tu rentres en prison. Il faut arrêter toutes ces méchancetés.

J'ai toujours l'espoir que tu sortes, et que tu deviennes quelqu'un de bien, et que tu regrettes le mal que tu as fait.

J'ai toujours l'espoir de retourner avec toi... je rêve toujours de toi...je ne perds pas espoir.

Manora 


\section{LETTRE FICTIVE (Babe)}

Le 16 mai 2012

Bonjour François,

Il y a déjà un petit moment que je n'ai pas usé de mon temps pour t'écrire. J'aurais aimé que tu daignes me répondre au téléphone, pour que nous puissions parler ensemble de nos filles. J'ai conscience que tu ne vois en moi qu'une simple criminelle, une vulgaire détenue, mais n'ai-je pas été la mère de tes enfants avant mon incarcération ? Où est passé le temps où tu étais celui qui partageait ma vie, qui voulait me protéger et protéger nos enfants? Il est dépassé le temps du chevalier venu de l'île de la Réunion...

Je ne t'en veux pas d'avoir ce sentiment de refus envers moi, mais tu es un père et ton devoir est de montrer à tes filles que la vie peut être semée d'embuches. Seulement, toi tu crées les problèmes, tu sèmes la pagaille dans l'esprit de nos anges.

Il faudrait que tu acceptes de m'écouter juste une fois pour que tu comprennes que nous avons fait ces enfants à deux et qu'il est donc de notre devoir de les élever à deux.

Cesse tes enfantillages, s'il te plaît.

J'espère que cette fois j'aurai une réponse, même négative, car cela prouverait au moins un peu ton engagement.

Allez, je crois avoir tout dit...

Salut,

Babe

\section{LETTRE FICTIVE (Manora)}

Le 15/05/2012

Chère Maman,

Je t'écris cette lettre pour te dire que je t'aime beaucoup et que tu me manques beaucoup. Je pense beaucoup à toi. Ne t'inquiète pas pour moi. Je vais bien. Il ne me reste pas beaucoup. Je sors bientôt inchallah. L'essentiel c'est que toi tu sois en bonne santé. $\mathrm{Ne}$ pense pas trop. Ce n'est pas grave que je sois en prison. Ce n'est pas la fin du monde. Ca me servira de leçon. C'est la première et la dernière fois. Prends soin de toi. Je t'aime très fort ma chère maman

Je t'embrasse beaucoup. Bisous,

Manora

\section{LETTRE FICTIVE (Maëlly)}

Ma chérie,

Je t'écris ce petit mot pour te dire à quel point tu comptes pour moi

Toi, ma meilleure amie, ma confidente,

la détentrice de tous mes secrets,

Toi, qui ne m'a jamais trahie, même dans le doute ou la colère

Tu ne m'as jamais déçue, même dans les moments difficiles

Avec toi, je ne connais ni la peur, ni le doute

Aujourd'hui je te remercie de ta compréhension, de tes attentions

Merci d'être là pour moi, comme une sœur, comme une mère

dans le meilleur comme dans le pire, là je peux te dire 
c'est toi ma seule et meilleure Amie pour la vie !

Merci de me donner cette force et ce courage.

Je t'embrasse bien fort mon amie. À bientôt.

Maëlly

\section{Personnages}

\section{ZOUBIR (Zohra)}

Zoubir est un jeune homme de 24 ans de la cité Berthe à Coulon. Il ne fait rien de ses journées. Il passe son temps à rêver et à s'imaginer. Il est plein d'ambitions.

Tout en squattant dans son quartier, il pense à sa réussite et à son avenir. Il a voté pour la $1^{\text {ère }}$ fois, Hollande. Bien sûr, en espérant le changement pour sa vie.

Les promesses, il connaît.

Il aime : squatter, fumer, son quartier, sa mère

Il aime pas : le racisme et les racistes, la prison, la justice

Il pense : à l'argent, à la belle vie, aux femmes

Il désire : Eva Longoria, gagner au loto.

\section{Textes libres}

\section{À TOI (Anonyme)}

Sur ces murs qui m'entourent

Sur les barreaux de ces fenêtres

Sur ces portes qui m'enferment

J'écris ton nom

Sur ce papier jauni

Sur ce lit qui me détruit

Sur ma peau qui se vieillit

J'écris ton nom

Sur ce ciel bleu

Nuageux, étoilé ou lunaire

Sur ce soleil imaginaire

J'écris ton nom

Sur ce chien qui aboie

Sur cette mouette qui me tue

Sur ces pigeons qui ma gâchent la vue

J'écris ton nom 
Sur les brisures de mon cœur

Sur la joie de mes pensées

Sur le fond de mes rêves

J'écris ton nom

Sur cette colline que je vois

Sur mon amour que j'ai pour toi

Sur cette vie qui m'éloigne de toi

J'écris ton nom

Je me bats

Je me construis

Je regrette de t'avoir détruite

\section{TOI MAMAN}

QUAND LA VIE EST UN CALVAIRE (Zohra)

Quand la vie est un calvaire

Chaque jour est un air

Quand la vie est une tristesse

Chaque jour est une promesse

Quand la vie est une prison

Chaque jour est une libération

Quand la vie est une loi

Chaque jour est un droit

Quand la vie est une liberté

Chaque jour est une envolée 


\section{C-L'Établissement Leclerc}

L'Établissement Leclerc a ouvert ses portes en 1961 et a cessé ses opérations le 30 septembre 2013 en raison d'infrastructures jugées inadéquates à la gestion des délinquants. Ce pénitencier à sécurité moyenne situé à Laval (Québec) pouvait accueillir près de cinq cents détenus. http://www.csc-scc.gc.ca/etablissements/001002-2008-fra.shtml

\section{Éric Charlebois @ l'établissement du Leclerc}

\section{CUVRES DES AUTEURS-PARTICIPANTS}

AFFABLE VISIONNAIRE... (Blacc)

- Entendez-vous ces murmures, ces chuchotements, telle une mélodie synonyme de printemps ?...

- Mais de qui parlez-vous ?

- De vous-même voyons !

- Je fais référence à votre « Moi intérieur », le véritable Moi...

- Le véritable Moi ?

- Oui, oui, votre véritable Moi...»

Pierre, étonné par ces paroles, s'interroge d'où provient cette voix. Ne sachant guère, il décide de contempler son environnement, mais ne reconnaît nullement ce lieu. Pourtant, avec ce décor paradisiaque qui s'offre à sa vue, Pierre se sent profondément seul, même très seul. Puis, au loin, il aperçoit à travers une intense lumière venant de nulle part, une éclatante silhouette s'avançant vers lui à grand pas. Si près, qu'en l'espace d'un clin d'œil, un homme fort avancé en âge se tenait debout à proximité de lui.

- $\quad$ Qui êtes-vous ? lui demanda Pierre.

- $\quad$ Je suis le Maître des Ténèbres, répondit-il.

Pierre avait du mal à comprendre comment cet étrange personnage qui se manifestait dans la lumière, pouvait se nommer le Maître des Ténèbres. Voyant que Pierre se questionnait à son sujet, le Maître lui dit : «Tout est clair pour celui qui est intelligent ».

- Mais diable, de quoi parlez-vous ? lui demanda Pierre.

- $\quad$ Je parle de ceux qui ont été éclairés dans la connaissance ésotérique. En d'autres mots, ce sont des initiés d'un quelconque mystère, lui répondit le Maître.

Perplexe, Pierre se dit en lui-même que le Maître faisait référence aux grands de ce monde, dont certains croient qu'ils participent à un gigantesque complot...

Toutes les religions de ce monde possèdent une branche mystique donnant un accès direct à tout ce qu'on appelle Dieu... sans passer par un prêtre. La Kabbale pour le judaïsme, le Soufisme pour l'islam, l'Opus Dei pour l'Église catholique ou les Rosicruciens et j'en passe... Tous ces mouvements ésotériques 
se rejoignent en un seul point, c'est-à-dire, pour connaître leur savoir, il faut préalablement être un initié, dit le Maître.

- Les livres sacrés comme la Bible par exemple, dont les initiés et les noninitiés puisent leurs informations, la traite-t-il de la même manière ? demanda Pierre.

- $\quad$ Non, car un initié de la connaissance ésotérique lira la Bible différemment d'un croyant chrétien ou juif. L'initié reconnaîtra le symbolisme, la numérologie et les codes ésotériques tandis que le croyant prendra le texte dans son sens littéral. Ainsi, le même texte agira comme moyen de transmettre la connaissance ésotérique aux initiés et créera une religion-prison pour les masses qui ne le sont pas, dit le Maître des Ténèbres.

- $\quad$ Alors, de quelle utilité est la religion ? demanda Pierre.

La religion apporte au croyant l'illusion de réconfort afin d'affronter la mort. Toute âme humaine doit être en mesure de connaître ces choses de leur vivant... Voilà pourquoi je me tiens en ta présence Pierre, dit le Maître des Ténèbres.

- $\quad$ Etes-vous ici pour me délivrer d'une mort certaine ? demanda Pierre.

- $\quad$ Bien au contraire Pierre, lorsque cette voix, c'est-à-dire ton Moi intérieur qui se tient en ma présence, murmurait et chuchotait dans ton for intérieur, elle le faisait afin de t'avertir de ma présence... dit le Maître.

- $\quad$ Je ne comprends pas, dit Pierre.

- $\quad$ Si tu avais pris soin de bien écouter cette voix, tu serais en mesure de constater que je suis en fait «l'Ange de la Mort », rétorqua le Maître.

- $\quad$ Mais, mais, ça veut dire... dit Pierre.

- Ça explique que tu n'avais pas la moindre idée que tu étais mort et qu'ironiquement Pierre, tu devras vivre avec... dit finalement L'Ange de la Mort.

\section{HORS CONTRÔLE (Anonyme)}

Il buvait son café sans hâte. Il était seul, libre, encore jeune et très beau. Dans une heure, il allait prendre son important vol d'avion. Bryan se préparait tranquillement, se brossait les dents, enfila sont plus beau complet, se regarda deux, trois fois dans le miroir pour savoir quelle cravate choisir. Après plusieurs essais, il choisit la bleue picotée de rouge que sa mère lui avait donnée en cadeau pour ses vingt ans. Bryan avait tout pour réussir, des diplômes à perte de vue qui dépassaient largement les attentes, un charisme fou, sans 
oublier un sourire ravageur. Sa mère, qui venait d'avoir cinquante-cinq ans, en était bien fière. Toute jeune, elle lui avait tout donné : amour, confiance et responsabilité dans la vie. Et voilà, c'est l'heure de partir. En route vers l'aéroport !

Quelques kilomètres plus loin, Bryan décide d'arrêter sa rutilante Mercedez au premier dépanneur qu'il voit. D'un pas, il bondit à l'intérieur et se précipite vers les journaux. Il acheta le Times et le ramena avec lui. Devant sa voiture se trouvait une magnifique demoiselle : cheveu noir, bronzage impeccable, une très jolie robe rouge en lin et un regard de braise. Cette femme, quelle femme ! Il enfonça sa main dans son veston pour y prendre son cellulaire. Il se rendit compte qu'il avait plusieurs messages de Sonia, il leva les yeux au ciel et s'écria : «Merde, je l'ai oubliée ! »Pendant ce temps, il continua de contempler la demoiselle qui était à ses yeux, tout simplement sublime. Il lui fit un sourire et un clin d'œil et remonta dans sa Mercedez noire.

D'autre part, à l'autre bout de la ville, debout dans son immense bureau orné de ses huit grandes fenêtres, la petite Sonia contemplait la vue que lui procurait son gratte-ciel. Avocate de profession, Sonia était une femme qu'on ne pouvait s'empêcher de remarquer. Son physique de rêve et ses cheveux blonds platine faisaient tourner bien des têtes. Elle portait une jupe blanche en cuir, ainsi qu'un chemisier rose bonbon et de jolis bottillons en suède noir. Comme vous pouvez le constater, elle est féminine jusqu'au bout des doigts. Peu de temps après, elle reçoit enfin l'appel de Bryan. Il lui dit :

- $\quad$ Désolé, ma belle, mais j’ai manqué tes appels.

- $\quad$ Oui je sais, j'ai essayé de te rejoindre à maintes reprises. C'est moi qui a ta précieuse carte à puce. Oh non c'est pas vrai ! Je n'ai vraiment pas le temps d'aller courir à l'autre bout de la ville ! T'inquiète, je vais te l'envoyer par message courrier delta.

Le service courrier à vélo, arrive dix minutes plus tard : un jeune garçon imberbe de dixhuit ans. Il salue Sonia et prit le paquet et lui dit :

- $\quad$ Merci madame !

Sonia détestait se faire dire «madame », elle travaillait assez fort sur son physique, mais vue la différence d'âge, c'était une question de politesse.

Le garçon saute sur son vélo et pédale à toute vitesse direction de l'aéroport. Toujours en chemin, il brûle toutes les lumières à une vitesse d'éclair. Rendu près du coin de Vallée et de Ferre, il roule sur une grosse flaque d'huile noire qui s'échappait d'un autobus. Il s'ensuit quelques manœuvres d'évitement, mais rien à faire, la perte de contrôle est inévitable... Le messager glissa comme s'il était sur une patinoire vers une voiture qui est déjà stationnée. Bang ! Il se fracasse la tête contre le pare-choc avant, sa jambe est coincée, il crie sa douleur : douleur qui est comme un couteau qui lui transperce la gorge. Quelques instants plus tard, l'ambulance arrive, le jeune garçon s'évanouit. 
Arrivé à l'hôpital, l'heure était critique il fallait à tout prix l'opérer ! L'infirmier en poste appelle la chirurgienne en chef. Une heure passe et le garçon est toujours sur la table d'opération. Pendant ce temps, Bryan est inquiet, nerveux, que se passe-t-il ? Où est ma carte à puce ? Tout à coup, son téléphone se met à vibrer dans sa poche de veston : une voix de femme lui demande s'il est bien Bryan?

- Oui, lui dit il, je suis Amanda la chirurgienne en chef de l'hôpital Université. J'ai un paquet pour vous en votre nom.

Alors, ils se donnent rendez-vous quelques heures plus tard pour quelle lui redonne sa fameuse carte à puce en personne. Rendu à destination, quelle ne fut pas la surprise de Bryan : robe rouge en lin, cheveux noir, bronzage impeccable, rouge à lèvres étincelant, elle était encore plus belle que ce matin!

Le courant a passé immédiatement entre nous. Nous avons échangé quelques baisers et on ne s'est plus jamais quittés. Aujourd'hui, nous sommes mariés depuis quinze ans et heureux dans nos professions. Amanda est devenue « maman à la maison » pour s'occuper de nos deux jumelles Sabrina et Sofia. Moi je suis toujours sous-gouverneur au président des Etats-Unis.

\section{LA BOÎTE (Lucie Chicoine)}

C'est à ce moment qu'il est entré dans la pièce.

Il y avait une boîte sur la table. «Voyons, se dit-il, elle n'y était pas ce matin... Qui avait bien pu la poser là ? » De plus, Jérôme se demandait à quoi pouvait servir cette boîte. Il l'observait et plus il la scrutait, plus il avait l'impression de la voir bouger.

- $\quad$ Je ne peux tout de même pas avoir peur d'une boîte, se dit-il, c'est ridicule.

Soudain, le couvercle trembla. Puis, des petits cris se firent entendre. La boîte semblait vivre comme si elle s'éveillait sous les battements d'un cœur. C'était une toute petite boîte qui vibrait tout en faisant entrevoir la vie. Dans un soubresaut, le couvercle se souleva un peu. La boîte tremblait, avançait. Une patte, toute petite s'infiltra dans la fissure. Puis, un joli minois, celui d'un petit chat fit surface.

Jérôme regardait avec surprise le chaton qui avait maintenant fait basculer la boîte. D'où venait-il ? Celui-ci sautait sur le fauteuil et regardait d'en haut le plancher qui lui donnait l'allure d'une crevasse. Sa candeur désarmait Jérôme, mais il n'avait jamais voulu de chat. Il avait beau aimer les animaux, tout son entourage savait qu'il était allergique aux chats et qu'il ne pouvait le garder à la maison.

Sur un coup de tête, il empoigna l'animal avec sa main d'où brillait une bague, anneau reçu lors de son mariage avec Joanne, il y avait déjà quelques années. Avec précipitation, il le remit dans sa boîte initiale. 
- $\quad$ Je n'ai pas de temps à perdre avec un chat !

Le minet miaulait plaintivement en grattant la boîte pendant que Jérôme s'affairait à se préparer à manger. Bien qu'en congé, il avait une journée pleine de petites tâches à accomplir. Tout à sa réflexion, il avait sorti la mayonnaise pour se faire un sandwich aux tomates. Cela ferait un repas vite fait qui comblerait sa faim. Il croquait maintenant à pleines dents les tranches de pain grillées en savourant la tomate fraîche cueillie du jardin, tout juste assez assaisonnée.

C'est vrai, Johanne avait gardé l'auto aujourd'hui, il lui avait dit qu'il prendrait l'autobus. Juste à penser à la chaleur de la rue et du fait d'être encombré dans ce moyen de locomotion, son air devenait grognon. En voulant mettre son assiette dans le lavevaisselle, celle-ci tomba en mille morceaux sur la céramique. S'il n'avait pas tellement l'humeur à la fête tantôt, elle ne s'était pas tellement améliorée... Il accrocha son sac et se mit à descendre les escaliers, quatre à quatre. Il courrait pour rattraper le temps perdu. Comme Jérôme arriva au coin de l'intersection, il vit son autobus lui passer au nez.

Les autos filaient dans tous les sens. C'est comme si la vie devenait folle en ce jeudi après-midi. La journée n'était pas bien commencée et elle s'enlisait de plus en plus. Des odeurs de carburant se mêlaient dans la chaleur estivale d'où s'élevaient des vapeurs émergeant de l'asphalte. Sur la rue, il héla un taxi, car son retard à son rendez-vous hebdomadaire s'aggravait. Peut-être que de cette façon, il pourrait arriver plus vite à destination. Mais il avait beau vouloir un taxi, Le temps passait, les minutes s'envolaient et les voitures étaient pleines de passagers. Aucune place disponible pour lui. Contrarié, la sueur perlait sur son front. Le stress de la ville lui grimpait au nez pour en venir à son comble. Mais pourquoi s'en faisait-il autant ? Il prit une grande respiration et celle-ci l'aida à se sentir plus « zen ».

Finalement, enfin, une d'elles s'arrêta pour lui.

- $\quad 3580$ rue St Firmin, s’il-vous-plait.

- Bien monsieur, répondit le chauffeur.

La route lui semblait longue, plus longue qu'à l'accoutumé : beaucoup de feux de circulation, toujours au rouge et des gens qui traversaient la rue, lentement, interminablement. Il éternua et s'essuya le nez d'un revers de la main. C'était une journée de canicule écrasante, il n'avait plus de patience. Ses yeux le piquaient. Mais pourquoi ressentir tant de pression? Sur le chemin, il voyait des enfants jouer avec des fusils à eau, tous entrés dans leur monde. Oui, il se souvenait, l'année dernière au chalet, il avait joué ainsi avec ses neveux. Des petits jeux simples qui avaient gardé tout leur charme, de générations en générations et qui pouvaient leur réserver tant de plaisir.

Pendant que le chauffeur l'emmenait voir Élise, sa sœur, il sortait une dame de cœur de sa poche. Pourquoi avait-il cette carte à jouer ? Il y avait bien longtemps qu'il n'avait joué aux cartes. Comment se faisait-il que cette carte précise se trouve dans sa poche ? Il 
ressentait un inconfort, comme si quelqu'un avait décidé de la suite des événements. Un autre éternuement. «Voyons, ne me dit pas que j’ai attrapé quelque chose », se dit-il !

Sa sœur habitait à l'autre bout de la ville. Un terrible accident avait fait qu'elle devait maintenant se déplacer en chaise roulante. Il y avait de cela déjà 2 ans. Depuis quelques mois, elle venait d'emménager dans un appartement accessible à sa situation. Malgré ses moments de découragement, elle avait laissé place à un grand courage. Il admirait la façon dont elle surmontait jour après jour sa nouvelle situation.

Arrivé chez sa sœur, celle-ci l'accueillit à bras ouvert.

Je suis contente de te voir, dit-elle en lui faisant la bise.

Il déposa son sac sur le sol. Celui-ci se mit à bouger. À leur grande surprise, une petite boulle poilue en sortit. À l'insu de Jérôme, le chaton avait grimpé dans le sac et avait trouvé par ce voyage, sa dame de cœur...

\section{MÉLODIE POUR LA VIE (Martin)}

Par ta candeur et ta grandeur,

Tu as su me rendre meilleur.

Avec tes rythmes et tes silences,

Tu m'entraînes dans le tourbillon de la dévotion.

Tu changes avec le temps,

Tout comme les saisons le font au fil des ans.

Tel une partition, tu fais vibrer mes émotions comme les notes qui sortent d'un violon.

Tu fais battre mon tambour à ta cadence qui, parfois, Est pourvu de défaillance.

Sur un air en ré majeur, tu me fais grimper tout en hauteur, Mais lorsque tu reviens en bémol, Je retombe au sol.

Blanche, noire, ronde ou croche, tu me façonnes de façon à me mettre à ta portée. Suis-je bête ? Trop sensible à tes reproches ou tout simplement en mal d'aimer?

Jamais, mais jamais rien, ne pourra égaler cette magie que tu m'as inculquée Et qui, aujourd'hui, m'a sauvé de ce mal sans merci.

Même dans mon sommeil, tu continues de m'inspirer, Bien que je ne sache où cela va me mener, je te suis sans hésiter. 
Peut-être bien que demain ne sera point et qu'aujourd'hui, Seule ta mélodie me permettra d'aller plus loin.

Maintenant que j'ai goûté à ta beauté et ta pureté, mon corps et mon âme ne peuvent que T'en redemander encore et encore et cela, jusqu'à l'heure de ma mort...

\section{SPA POUR L'ÂME (Sébastien)}

La première chose qu'elle a remarquée c'est ce drôle d'objet qu'il tenait. Ce n'était pas un casque ni un chapeau. On pouvait dire qu'il y avait une genre de corne par-dessus. Et lui, si fier de lui comme s'il était le chef de la tribu. Mais l'était il vraiment? Elle songea un instant. Puis elle avait l'impression que c'était peut-être un imposteur. Comme s'il essayait toujours de contrôler la situation... Un vrai chef l'était ! Donc pourquoi trouvaitelle qu'il faisait semblant ? Peut-être qu'il la rendait mal à l'aise, se disait-elle. Après réflexion, elle ne l'aimait pas vraiment. Elle se disait que le vrai guerrier est un guerrier et ne prétend pas l'être. A-t-elle vraiment fait tout ce chemin pour écouter cet homme toute la nuit ? Et tous les autres assis, qui l'écoutaient comme des brebis... On dit souvent que le fruit ne tombe pas loin de l'arbre. Pourtant il ne ressemblait guère à son père. Lui, qui était si calme, mais si puissant ! Et toutes ses balivernes... Pour un grand chef, tout cela devenait monotone.

Mais un instant, pourquoi demandait-il à tous ces gens de signer leur nom sur le calendrier ? Sandrine semblait être confuse. Elle, qui est venue chercher la paix et un certain répit... Les jambes engourdies, comme si elle ne pouvait quitter la pièce. Même s'il n'y avait pas d'horloge, elle avait l'impression que le temps passait très vite. Étrange... Elle arriva avec son entourage, mais se sentait si seule, si loin. Tantôt une cornemuse, maintenant une lampe et la température qui montait graduellement dans cette salle. Et cette table couleur or en forme triangulaire qui dégageait une certaine odeur... L'atmosphère devenait de plus en plus lourde. Par contre, elle se méfiait de moins en moins. C'est comme si, à la longue, elle acceptait ce qui lui arrivait. Des sons iconiques qu'elle n'avait jamais entendus, la faisaient voyager dans son esprit. Je ne sais si elle s'en rendait compte. L'atmosphère, composée de brume invisible la calmait cependant. La salle en transformation constante faisait en sorte qu'elle ne voyait, sentait et n'appréhendait plus personne. Son souffle se faisait de plus en plus détendu. Sans compter que le fier à bras ne l'incommodait plus. Comme si par magie, la pièce se vidait. L'innocence de certains pourrait être fatale ! Bof, et puis plus rien, plus aucun souvenir.

Le lendemain matin lors du réveil, Sandrine, sa mère et sa sœur se sentaient beaucoup mieux. Elles plièrent bagages et repartirent bien heureuses de la méditation nocturne.

Quelques semaines plus tard, Sandrine s'apercevra que toutes ses économies avaient disparu de son compte d'épargne... Ne comprenant rien, elle décide d'appeler sa sœur pour lui parler de cette mésaventure. Elles décidèrent d'aller à la banque pour en savoir plus sur la situation. Rendue sur les lieux, Sandrine attendait de parler au gérant de la succursale. Pendant ce temps sa sœur vérifia son compte après avoir fait un retrait. Stupéfaite, elle réalisa que son capital avait lui aussi disparu. 
Le gérant ne pouvait lui expliquer cette disparition pour le moment, mais il lui donna un rendez-vous pour la semaine suivante. Puis, quand les deux sœurs en parlèrent à leur mère, la femme âgée leur confirma que la même chose lui était arrivée. Par contre, la mère semblait un peu plus gênée de la situation. Suite à cela, Sandrine dit : « Notre argent a été transféré dans un compte suisse. En plus, les transactions ont toute notre signature à plusieurs reprises. »

Mais qui les a flouées ? Reverront- elles la couleur de leur argent un jour?

\section{UN SOUFFLE DU MOYEN-ORIENT (A)}

J'aimerais vous raconter une histoire qui se passe dans une époque très ancienne, vers l'an 800 après-JC au Moyen Orient dans l'ancienne Perse. Dans une grande ville qui s'appelait jadis «Shiraz » il y avait un petit garçon qui s'appelait Ali, il était orphelin et âgé seulement de 11 ans. Il n'avait jamais connu son père et sa mère était décédée quand il était âgé de 8 ans, ce qui veut dire qu'il vit dans la rue depuis au moins 3 ans. Habitué à vivre à proximité du souk, témoin de toutes sortes de situations, Ali est devenu très vite une personne habile et débrouillarde.

Une nuit, Ali dormait paisiblement dans l'entrée d'une maison. Celui-ci est réveillé en sursaut par du vacarme. Alors, il est allé investiguer et il est tombé face à face avec une douzaine d’homme masqués et à dos de chevaux. Ils étaient en train de dévaliser un marchand de pierres précieuses. Surpris d'être observé par le petit Ali, les bandits décident de l'enlever et de l'amener avec eux. Le petit Ali se demandait ce qui allait lui arriver.

Rendus à leur cachette, ils se rendent à leur caverne secrète dans une montagne rocheuse en dehors de la ville de Shiraz. Les bandits présentent le petit Ali à leur chef «Jaffar » et celui-ci s'est mis à interroger le petit Ali sur sa vie. C'est alors qu'il a décidé de l'adopter.

Quelques années plus tard, le chef Jaffar est décédé et le petit Ali maintenant grand, fort et rusé a pris la place du chef. Et voilà : le conte D'ALI BABA ET LES 40 VOLEURS EST NÉ. 


\section{Guy Thibodeau et le conte @ l’Établissement du Leclerc}

\section{EUVRES DES AUTEURS-PARTICIPANTS}

\section{LE LION DE LA JUNGLE (Beenie)}

Il était une fois, dans la savane africaine, toutes les sortes d'animaux sauvages et domestiques. Il y avait des lions, des léopards, des gazelles, bref il y avait un peu de tout.

Le roi de la jungle, le lion, convoqua tous les animaux à son rocher pour une assignation. Le roi avait besoin d'un messager pour livrer ses messages dans son royaume qui s'étendait du lever du soleil jusqu'au coucher de celui-ci.

Tous les animaux du royaume ont répondu en grand nombre à l'invitation. Un lièvre qui était sur la file d'attende remarqua à son côté une tortue. Il lui dit : "Qu'est-ce que tu fais là ? » La tortue lui répondit : «La même chose que toi ! » Le lièvre partit à rire en se moquant de la petite tortue.

- $\quad$ Tu es trop lente, tu ne seras pas capable !

La tortue lui répliqua :

- $\quad$ Combien tu paries ?

- $\quad$ Dix pièces d'or ! répondit la tortue.

Le pari était lancé, tout les deux sont partis pour se lancer dans cette aventure. Le lièvre, sûr de lui, part au galop comme une flèche. Quant à la tortue, elle s'en va lentement, un petit pas à la fois.

Après une bonne heure de course, le lièvre s'aperçoit que la tortue était loin mais très loin derrière lui. Il décida de prendre une petite sieste sous l'ombre d'un arbre. Il s'endort étant sûr de lui. La tortue continuait un petit pas à la fois sans jamais s'arrêter. La tortue passa devant le lièvre et s'aperçoit qu'il est en train de dormir... Elle continua, un petit pas à la fois comme elle faisait depuis le début de la course.

Soudainement, le lièvre se réveilla et vit que la tortue filait jusqu'au point d'arrivée. Il s'élança à tout allure pour essayer de rattraper son adversaire. Mais dommage, il était trop tard. La tortue venait à peine de franchir la line d'arrivée.

Finalement, d'où le dictons « rien ne sert de courir, car il faut partir à point. » 


\section{CE JOUR-LÀ (Lucie Chicoine)}

Il était une fois, une journée d'automne ressemblant à tant d'autres. Le ciel était d'un bleu poignant et malgré le soleil qui brillait de tous ses feux, un vent frais caressait les cheveux de la petite Claire. Elle s'était empressée de prendre son sac et avait couru vers l'école où toutes ses amies l'attendaient et jouaient en attendant la cloche. Sur son chemin, des arbres gigantesques se balançaient en faisant doucement parler leurs feuilles.

- As-tu vu Claire? disait l'un.

- Oui, répondait l'autre, quelle étourdie !

Encore une fois, elle était arrivée à temps en classe, mais de justesse... Heureusement pour elle, car elle ne tenait pas à avoir de retard non motivé. Pendant l'avant-midi, son regard se tourna vers ces grands arbres que le vent agitait. Bien qu'étant assise dans la classe, son esprit était vraiment ailleurs... Elle regardait les jaunes, les orangés des feuilles se mêler à travers les verts, les ocres et leurs rouges vibrants. Comme c'était beau, tout ce mélange de couleurs automnales se découpant dans l'azur du ciel. Sous les grosses bourrasques, elle voyait des centaines de petits hélicoptères qui quittaient l'arbre, tels de minuscules parachutes, et descendaient au sol pour en recouvrir le trottoir.

«Les amours, les travaux

Même le chant d'un oiseau

Ton cœur, mes mots,

Font tourner le monde. »

- Claire, comment épelle-t-on « fantastique », lui demanda l'enseignante.

- Euh...

Tout étant dans ses rêveries, elle n'avait pu répondre du tac au tac et avait manqué à la demande du professeur. Honteuse mais docile, elle essaya de suivre le reste du cours même si son cœur était déjà sous les grands arbres. Puis, son esprit fut emporté dans les cours de français et de mathématique et elle se mêla tant bien que mal à ses camarades de classe durant toute la journée.

Bien qu'elle lui semble interminable, celle-ci s'achevait. Un brouhaha s'éleva dans la classe pendant que les élèves se levaient pour préparer leur sac d'école de devoirs ou de leçons qu'elles avaient à préparer pour le lendemain. Claire avait hâte à ce moment, elle savait qu'elle aurait enfin un répit, elle ne pensait qu'à courir à l'extérieur.

C'est avec joie qu'elle fut sur le chemin du retour à la maison pour marcher dans les samares entassées au sol en petits monticules. Le vent s'était élevé et secouait la blonde chevelure des érables. C'était encore plus beau vu d'en bas : les samares tournaient mille fois sur elles-mêmes pour atterrir au sol et il y en avait plein ! Claire courait en élevant les bras au ciel tant elle était à sa joie du moment. C'était un temps magique, tout en simplicité.

Comme elle voulait conserver une parcelle de ce bonheur, elle se mit à ramasser les plus belles, les plus parfaites, celles où la petite aile n'était pas endommagée. Mais il y en avait tant, qu'elle ne savait lesquelles privilégier : elles étaient toutes belles !

Arrivée à la maison, elle ne savait que faire de son merveilleux trésor. Sa mère ne serait sûrement pas d'accord qu'elle mette cela dans sa chambre alors elle décida de creuser un petit trou, tout 
près de la maison pour les mettre en sécurité. Satisfaite de son idée, elle s'affaira à la tâche avec l'aide d'une roche qu'elle trouva tout près.

Puis, la vie étant ce qu'elle est, elle oublia le secret qui dormait sous terre. L'automne entraîna des journées de plus en plus fraîches, même froides. Ensuite, la neige se mettant de la partie, l'hiver recouvra le sol d'un manteau épais de mille cristaux. Les jeux d'hiver avaient pris la place : glissades, jeux de billes ou de construction de forts prenaient la vedette dans le cour de Claire et de ses petites amies.

«Une saison pour semer

Une saison pour attendre,

Les automnes les plus tendres

Ont pris source au mois de mai. »

« Les amours, les travaux

Même le chant d'un oiseau

Ton cœur, mes mots,

Font tourner le monde. »

Mais inlassablement, le rythme des saisons poursuivait sa course. L'hiver s'adoucit, les jours se firent plus caressants, les glaçons se mirent à fondre sur le toit des maisons. L'air tiède sentait même parfois une odeur sucrée de sirop d'érable. Le printemps était arrivé. La terre s'échauffait et buvait toute la neige fondue.

Incroyablement, alors qu'on aurait pu penser que la terre était morte, on se mettait à l'évidence qu'elle n'était qu'endormie d'un long sommeil. Car la terre s'éveillait en dépliant ses longs bras et en baillant de son souffle doux. La chaleur verdissait les gazons et la nature déployait des milliers de bourgeons verts tendres. Les oiseaux, plus discrets pendant la saison froide, faisaient leur apparition dans un cortège de gazouillis enchanteurs.

« Je cherche pour mes enfants

De quoi se faire une ronde

Pour faire tourner le monde

Sans contrarier le vent. »

« Les amours, les travaux

Même le chant d'un oiseau

Ton cœur, mes mots,

Font tourner le monde. »

Ce soir -là, ce fut au souper que la mère de Claire leur exposa :

- En travaillant à mes plates-bandes, j'ai vu des érables en dessous de la galerie, il ne faut pas laisser cela pousser là, dit-elle.

- C'est à moi, cria Claire, ce sont mes érables ! Il ne faut pas les tuer !

La vie avait fait pousser trois petits érables des merveilleuses samares que Claire avait recueillies. Peu après, les parents de Claire, accompagnés de la fillette, ont replanté les trois petits à des endroits plus stratégiques de la cour. 
Aujourd'hui, comme ils sont devenus des arbres magnifiques, c'est eux qui balancent leurs feuilles et, à chaque automne, ils laissent échapper des milliers de petits hélicoptères pour faire la joie des enfants. C'est ainsi que le cycle de la vie et des saisons se poursuivit.

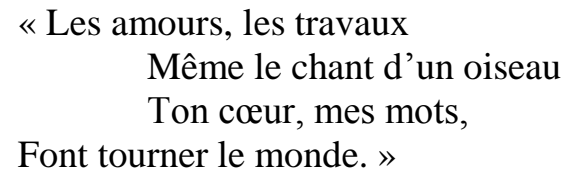

Chanson : Gilles Vigneault

\section{VIEILLE ÂME (Sébastien)}

Il était une fois un vieux pêcheur qui habitait au lac des Forets. Lui, il aime la nature et en prenait soin, comme à la prunelle des ses yeux. Il passait, donc, une bonne partie de la journée à pêcher. Il pêchait plusieurs espèces dont une très rare. Il aimait aussi aider les gens du village.

Or, un jour, il fit une étrange rencontre : il rencontra trois hommes qui lui font une offre assez inusitée. En effet, l'offre était spéciale, ils voulaient offrir un nouveau bateau de pêche au vieillard. Mais en échange, les intrus veulent que l'homme leur montre les meilleurs coins de pêche pour capturer ce poisson rare. L'espadon d'eau douce est présent dans le lac des forets seulement.

Le vieux pêcheur n'est pas convaincu de l'offre faite par les messieurs. Il déclina l'offre. Seulement ces drôles de gens ne cessaient de le harceler jusqu'à temps qu'ils acceptent. Puis un jour, ils débarquèrent avec leurs gros bateaux et leur attirail de pêche. C'est donc là qu'ils sont partis pour cette expédition. À bord du bateau, il aperçoit des plans pour sortir une bille du cerveau, celle qui vaut une fortune en Asie. C'est alors que le vieil homme constata qu'il se faisait rouler par des traficant d'ivoire et de boule d'espadon.

Le vieillard était fou de rage mais il ne dit rien à l'équipage et continua à pêcher comme si rien n'était. Il élabora un plan pour les anéantir à jamais. Et puis, tranquillement, l'équipage s'approcha près de la chute du diable. Bien doucement, sans même le savoir, il se dirigeait vers la mort assurément. Le seul hic c'est que le bonhomme avait un plan pour se sauver sans conséquence. Il se disait que s'il n'avait pas de pitié pour la nature, il n'en avait pas pour eux.

Il savait à quel moment sauter du bateau pour ne pas être anéanti vers la mort. Il effectua enfin la manœuvre et se sauva.

En rentrant au village, il donna le nouveau bateau aux enfants pêcheurs. Eux étaient heureux et lui aussi. 


\section{Tina Charlebois et la poésie @ l'établissement du Leclerc}

GEUVRS DE L'AUTEURE-ANIMATRICE

\section{LA SEMENCE}

«Viens voir mes champignons!»

Un doigt crochu et un hochement de tête

m'entraînent vers ce réceptacle

de terre moulue

où grandissent fungus et fioritures

«On les a arrosés pis arrosés »

Nourrir des moisissures

pour ne pas moisir soi-même

entre le béton et les bavures

qu'on ne sait jamais raturer

« Ils poussent d'eux-mêmes ;

ils se sont développés tu' seuls »

En l'absence de fumier

on pâture parmi les nutriments à proximité

les multivitamines de carence

«Je vais les cultiver pis les vendre »

Un sourire en coin

laisse voir le malin qui volait

le premier biscuit de l'assiette

celui qui malgré l'espièglerie

ne cherche qu'à plaire à celle

qui bêche ses semences de l'intérieur

\section{LES CONSTATS PROFANES}

Les Simpson à 4:00, c'est sacré

me dit-on en guise d'excuse

pour l'écoute entrecoupée de dérapages

La routine rassure

ceux qui ne susurrent

que les chuchotements d'un passé sans avenir

Elle s'impose comme un poil de chat

dans le bol d'eau d'un caniche albinos

S'évader d'une salle de classe

où la prison se glisse dans les chapitres

de romans mensongers

Si le manque de télé est sacrilège

les lacunes d'une fausse réhabilitation

sont profanation d'une société blasphématoire 


\section{GUVRES DES AUTEURS-PARTICIPANTS}

XO (Beautiful Young)

Quand tu es en moi

tu m'allumes comme du gaz d'avion

Je te sens couler dans mes veines

comme une bouteille de miel

Ton goût de velours

me rappelle à toi ma belle

Ta couleur café

me fait gaspiller tout l'argent que j'ai

Malheureusement tu es toujours un bonbon

qui me fait finir en queue de poisson

Avec toi je suis roi

tout comme moi tu es hors la loi

Ta chaleur m'inspire

comme un vieux souvenir

qui me fait craindre le pire

Menotté

Emprisonné

Je retourne à mon passé

Miroir ou lumière

je scintille tout en me faisant reluire

Vendredi samedi Rémy

Copain mesquin Martin

C'est le début de la fin !

RÉMY MARTIN

\section{MON DERNIER BAISER... (Cruzéo)}

C'était les petites heures du matin, une belle soirée venait de s'écouler Quand elle s'est approchée de moi pour se mettre dans le creux de mon cou... Elle se redressa et me regarda faisant signe de lui donner un baiser.

Je me suis retenu, question de la taquiner.

Elle me jeta un air fâché, je lui lance un petit rictus

Et me jeta sur ses lèvres pulpeuses...

Ce moment dura une éternité dans ma tête

Mais dans le monde réel, ce ne fut que quelques secondes

Un instant inoubliable juste avant de m'encager... 
DOUBLE BIG MAC BACON ! (Mina)

Mes cinq sens s'excitent devant le grand $\mathbf{M}$

L'extase d'avoir une gâterie que j'aime...

L'envie d'avoir ma bedaine pleine,

Enlève ma douleur de la faim,

Mais peut-être que ce n'est pas sain...

Mon estomac crie famine,

Devant le gros sandwich qui s'illumine.

Le goût du Big Mac m'assassine,

Devant le joyeux festin qui se termine.

C'est la fin de ma faim...

\section{LA PÊCHE (Sébastien)}

Tu peux être en plein centre-ville

Comme au château de Montebello

Quand j'ai les deux pieds dans l'eau,

Je me sens comme un aigle

Qui sillonne le long d'un rocher.

Seul ou avec un ami

C'est le paradis

Quand je l'ai au bout de ma canne

Et que je sens le fil sortir de ma bobine,

Mon cœur palpite

Et je deviens anxieux

À savoir si je le sortirai de l'eau...

Ou s'il gagnera le combat !

Que l'attaque soit féroce ou timide,

Je ressens un grand bonheur inexplicable

Quand la tension est entre moi

Et ce gros achigan!

C'est comme gagner à la loto à chaque fois

Et quand c'est un trophée,

C'est le jackpot

Et je capote...

Plus tard, on le concocte en papillote

Ou frit sur un lit de riz...

Bon appétit! 


\section{SITES EN MILIEU COMMUNAUTAIRE}

En plus des établissements de Joliette et du Leclerc à Québec ainsi que le centre pénitentiaire de Marseille, trois sites communautaires ont accueilli des ateliers d'écriture. Il s'agit respectivement de la société Élizabeth Fry du Québec à Montréal et à Gatineau, de l'organisme Les Impatients (Montréal) et de la Rue des Femmes (Montréal). Voici la consécration de ces ateliers, à savoir les textes produits à l'intérieur de cette initiative.

\section{A-Société Élizabeth Fry du Québec}

La Société Élizabeth Fry du Québec a été fondé en 1977 à Montréal pour venir en aide aux femmes ayant des démêlés avec la justice. Elle met à la disposition de sa clientèle une variété de ressources et de services: hébergement, soutien en milieu carcéral, supervision, programmes en matière de prévention et de réinsertion. Des ateliers ont été réalisés à la maison mère ainsi qu'à l'un de ses sites satellites en Outaouais : le Centre Élizabeth Fry de l'Outaouais. Depuis 1999, il dessert une centaine de femmes de la région. En termes d'ateliers, c'est là qu'ont eu lieu ceux mis en forme par Alberte Villeneuve, Lise Careau et Sylvie Frigon. En amont, c'est aussi à cet endroit que le spectacle-partage a pris vie sous la direction de Valérie Descroisselles-Savoie et Louise Poirier.

http://www.elizabethfry.qc.ca/

\section{ALBERTE VILLENEUVE @ ÉLIZABETH FRY}

\section{J'Y ARRIVERAI UN JOUR ! (HISTOIRE PLEINE D'ESPOIR) (Ensoleillée)}

«Le vrai bonheur est dans le calme de l'esprit et du cœur. »

C'est l'histoire d'une jeune femme qui vivait le désespoir dans une prison de consommation. Elle rêvait d'une vie meilleure, d'un sauveur, d'un prince charmant qui changerait tout...

Un beau jour, son rêve s'est réalisé mais, comme le jour s'abandonne avec le coucher du soleil pour faire place aux ténèbres de la nuit, son rêve est vite devenu un cauchemar rempli de déceptions et d'abus. La jeune femme a voulu retourner dans sa prison de consommation.

Pendant des jours sans soleil et des nuits sombres, elle s'est démenée pour retrouver l'équilibre et l'espoir, cette lueur cachée au plus profond de son coeur, qui viendrait changer le cours de sa vie.

Un jour enfin, elle a compris qu'elle seule devait se charger de changer sa vie. Elle en avait le pouvoir. Plus d'affronts, de luttes insensées; elle voulait colorer sa vie à l'aide d'une nouvelle palette de couleurs. Le changement a été graduel... un jour à la fois. Redécouvrir le goût de vivre à petites doses... le plaisir de commencer la journée du bon pied en savourant un bon café, prendre le temps de s'occuper de soi, de ses besoins et des gens qui l'entourent, réapprendre à aimer et être aimée. 
En acceptant l'aide qui lui était offerte et en suivant les conseils des professionnels, aujourd'hui elle imagine les choses autrement. Elle se voit dans un métier d'accompagnement auprès de gens dépourvus, souffrant d'handicaps physiques ou émotifs. Elle ressent ce besoin de répandre des ondes positives et une lumière bienfaisante dans ces vies assombries par la maladie. Elle le comprend bien, beaucoup de gens éprouvent de la difficulté à voir la lumière au bout du tunnel quand leur misère intérieure les étouffe et que leurs pensées s'embrouillent.

Il faut savoir que le bonheur dans la vie dépend de la qualité de nos pensées. Elle voudra leur dire: "Puisqu'on vit tous dans la même lumière, il faut juste un peu plus d'amour que d'ordinaire. »

\section{LISE CAREAU @ ÉLIZABETH FRY GATINEAU}

\section{COMME UN GRAND BATEAU (Lise Careau)}

Il y a des crapauds

Il y a des anges

Il y a des désirs insensés à enterrer sous les roches

Il y a des montagnes dans mon cœur

Et dans ma cour, un ruisseau perdu

Comme un grand bateau parfois, la nuit m'emporte

As-tu vu l'amour dans la lumière du jour

As-tu vu l'oiseau

As-tu vu l'orage noircir le ciel

Et le vent chasser les nuages

As-tu vu le soleil

As-tu vu le soleil lécher le mur de briques

Lécher le trottoir et le dos du chat

As-tu vu le sable rouler sur l'asphalte

As-tu vu l'eau s'allonger sur la plage

As-tu vu la clé de ton château briller au fond de ton coeur

As-tu vu les ronds dans l'air que font tes rêves

As-tu vu les étoiles collées à ta fenêtre

As-tu vu l'herbe fleurir dans les fissures du mur

As-tu vu les enfants jouer à être grands

Il y a des crapauds

Il y a des anges

Il y a des désirs insensés à enterrer sous les roches

Il y a des montagnes dans mon cœur

Et dans ma cour, un ruisseau perdu

Comme un grand bateau parfois, la nuit m'emporte 
J'AI CONFIANCE (Lise Careau)

J'ai confiance que toutes les fleurs connaissent leur printemps

Au moins une fois

J'ai confiance en nos capacités d'éclosion

Confiance dans la nécessité du rêve et la valeur des larmes

Confiance dans la lenteur du souffle et l'ampleur des rencontres

Confiance dans la raison du corps et la nature des choses

Confiance dans la joie profonde et la nuit étrange

Confiance dans la tendresse des hommes et la force du poème

MON ANGE (Céleste)

À l'aube de mes quarante ans

J'ai découvert un ange, quelle beauté !

Parfois si près

Parfois si loin

Merci d'être venu dans ma vie

Tu as rallumé ma flamme

Je t'ai attendu toute ma vie

Maintenant je sais que tu existes

De près, de loin

Un jour, déploieras-tu tes ailes pour moi ?

Je t'ai donné les clés de mon cœur

Toi, tu es parti avec un souffle de moi

Te reverrai-je encore une fois

Ou m'as-tu pris ce que j'avais de plus précieux :

Croire en toi ?

QUAND PLUS RIEN NE VA (Lise Careau)

Quand plus rien ne va... plus rien ne va

Il y a les arbres, les nuages, le bruit de mes pas

Quand plus rien... vraiment plus rien ne va

Il y a toujours la vie qui coule en moi 


\section{Valérie Descroisselles-Savoie @ Élizabeth Fry Montréal}

\section{LETTRE À MON FILS (La Puce)}

\section{POUR TOI STEPHEN DE MAMAN \\ JE T'AIME FORT}

Salut mon grand. Comment vas-tu ?

Moi ça pourrait aller mieux si j'étais avec toi car tu me manques vraiment.

Quand je serai sorti, je vais passer du temp juste avec toi car je veux me rapprocher de toi pour le nombre de jours que je n'ai pas été présent. N'oublie pas que je pense toujour à toi et je fais beaucoup de choses pour sortir d'ici. C'est sûr, je vais avoir des conditions et des heures sévères, mais c'est mieux que rien du tout. Là où je vais aller, tu vas pouvoir venir dormir, mais il y a des règlements pour toi aussi. Mais les tiens sont corrects. Voici ce que je t'écris pour toi. Tu as du prix à mes yeux, tu as de la valeur et je t'aime.

\section{MA MÈRE (La Puce)}

C'est une mère qui a su élever ses deux filles du mieux qu'elle pût. Nous étions deux et ce n'était pas facile. Avec le temps, elle s'est rendue bien malade. Je n'étais plus à ses côtés. Pourquoi la maladie ? C'est une mère précieuse à mes yeux. Je suis fière de l'avoir comme mère, même si je n'ai pas été là pour elle depuis 4 ans. Je peux lui dire un gros merci aujourd'hui pour m'avoir donné la vie. Sans toi, je ne serais pas là.

Merci. Je peux te dire mille mercis et mille je t'aime.

Tu resteras la meilleure maman du monde.

La Puce

\section{POURQUOI DANS MON CEUR (La Puce)}

Pourquoi ces montagnes russes dans mon cœur me font perdre la tête ?

Pourquoi ce mal de vivre

Ne cesse de me poursuivre?

Pourquoi dans mon cœur toute cette angoisse

Comme un morceau de papier se froisse et se défroisse

Pourquoi je tremble si fort dans mon cœur.

Et que j'ai encore peur comme un enfant dans la noirceur?

Où es-tu toi supposée sérénité ?

Pourtant, je n'ai jamais cessé de te chercher

Combien ça coute de sortir du trouble?

Pourquoi ai-je toujours l'impression.

D'être toujours seule au fond 
Y-a-t-il un escalier pour remonter ?

Combien ça coute pour sortir de la voute?

Depuis ma naissance

J'ai aperçu mon enfant

J'ai entrevu mon adolescence

Et je cherche encore ma maturité

Maintenant je suis troublée

De l'enfance détournée

De la demarche accélérée

Du mauvais chemin emprunté

Mais qui suis-je

Toutes ces questions me donnent le vertige

Je suis comme une vagabonde

Coupée du reste du monde

Sera-t-il possible un jour

De prendre le bon chemin

Et d'y marcher très loin

Jusqu'au petit matin

Sera-t-il possible un jour

D'oublier mon passé

De ne plus y retourner

Pour qu'enfin ma vie soit ensoleillée...

Novembre 2011

\section{Valérie Descroisselles-Savoie et Louise Poirier @ Élizabeth Fry Gatineau}

Cette initiative menée à l'automne 2010 s'inscrit en amont du projet des rencontres littéraires. Dans le cadre du séminaire de maîtrise intitulé Genre enfermement et créativité (CRM6780A) et donné par Sylvie Frigon à l'Université d'Ottawa, des étudiants ont participé à des ateliers de création littéraire animés par Louise Poirier. Ils ont répété l'expérience cette fois aux côtés de femmes en milieu communautaire. Le tout s'est soldé par un spectacle-partage de slam-poésie où les membres du public étaient invités à la représentation.

PORCELAINE (Sophie Cousineau)

Le cadeau de ma naissance

Un héritage indicible

Une genèse en déchéance

Et des souffrances invisibles 
Une enfance à l'hôpital

Des souvenirs intraveineux

Un microcosme de malades

Quelques chagrins ulcéreux

Un séjour en ambulance

Quelques lunes emplâtrées

Opération délivrance

Épisodes paralysés

Je ne suis plus rien vraiment

Qu'une dame de porcelaine

Qui se rompt à chaque moment

Sous les cris, sous les peines

Attention, je suis fragile

Éloignez-vous de moi

Femme aux os de verre

Femme aux os d'argile

Mon corps bassin d'illusions

Qui frime et trompe sans pudeur

Mes yeux, ma seule trahison

Tout s'effrite à l'intérieur

Un ange aux ailes de plomb

À la cellule despotique

Qui traîne une condamnation

Où chaque pas est un risque

Je suis un vase rapiécé

Par des gestes maladroits

Qui menace de s'émietter

Au prochain désarroi

Au quotidien, elles me hantent

Ces tortures voraces

Elles voyagent, elles sont errantes

Me mordent avec audace

Chaque jour est une guerre

Où mon bataillon résiste

Je ne serai point une mère

Je porte trop de cicatrices 
J'incarne la décadence

Je me noie dans les vapes

Et j'accrois les dépendances

Pour ainsi garder le cap

Je traîne les désillusions

Et un soupçon d'amertume

Un bagage en mutation

Qui se fondra dans la brume

Les traces de mon parcours

Seront inscrites à rebours

Sur le squelette morcelé

D’une existence empruntée

\section{Sylvie Frigon @ Élizabeth Fry De Gatineau}

\section{Lettres fictives}

\section{À : LA PREMIÈRE ET LA DERNIÈRE, QUI SAIT ME COMPRENDRE (Eva Luna)}

J'ai vécu jusqu'à présent, dans le néant, Je suis une incomprise, qui n'a jamais lâché prise.

Je suis souvent entre mon passé et ma réalité.

J'ai le goût d'avancer, de changer et d'explorer.

L'envie de réussir et enfin grandir.

Je dois apprendre à m'aimer ainsi qu'à aimer.

Les choix que je prends, je les assume et $\mathrm{j}$ 'apprends

Ma chance d'avoir deux beaux enfants qui me donnent

la joie et l'énergie d'aller toujours de l'avant.

Prendre la liberté de pouvoir changer, pour moi c'est d'arrêter de passer à côté.

Cesser de fuir enfin, et de me sentir bien.

Ma vie est totalement basculée. Je veux bientôt arriver

à contempler les jours et de les apprécier.

L'insécurité que je vis m'apporte à vouloir changer.

Je donne toutes mes énergies pour rétablir ma vie,

Souvent, je me demande : «Est-ce que je fais les bons choix ? Est-ce que je vais vivre encore une déception?»

Lorsqu'on construit une maison, on commence par la fondation.

Je dois fouiller mon passé et me rendre à l'évidence, qu'il m'a beaucoup ébranlé, marqué. Je ne peux oublier, mais je peux choisir de ne pas m'attacher au passé. 
Après coup, je vais commencer à couler mes fondations.

Prendre un jour à la fois, le temps et la force et les ressources.

Pour que mes enfants et moi soyons heureux et bien dans notre nouvelle maison.

Maman vous aime les gars.

\section{Texte libre de prose (Élizabeth Fry Gatineau)}

\section{SOPHIE}

Savoir et ne pas agir ce n'est rien savoir du tout. Je sais, je sais, je suis c.v. de thérapie, j'en ai fait de 31 ans à 51 ans. Digestion d'émotions trop longtemps refoulées. Est-ce que je retrouve ma liberté ? Elle s'est assez effacée ! Fini d'être étiquetée. Honnêteté. Fini la violence. Je veux retrouver mon enfance. Laisser tomber les gants de boxe et retrouver mon enfance.

\section{Sylvie Frigon @ Les Impatients}

Les Impatients est un organisme qui œuvre depuis 1999 auprès des personnes en santé mentale. On retrace ses débuts aux activités menées par la Fondation de l'art thérapeutique et des arts bruts du Québec en 1992. Fonctionnant d'après le principe du dedans au dehors, des ateliers artistiques encadrés sont mis sur pied et des initiatives assurent la diffusion des œuvres au grand public.

http://impatients.ca

\section{PRÉSENTATION DES AUTEURS-PARTICIPANTS}

\section{LEE}

Ayant vu le jour durant le précédent millénaire, LEE compte assez d'années de vie pour revendiquer le statut de monument. Heureusement, son statut d'incognito, qui lui sert de refuge, se situe à l'abri des pigeons...

-Je suis gentil, j'aime communiquer avec les autres. J'aime beaucoup participer aux activités des Impatients. J'aime beaucoup la musique et les arts, j'en ai besoin pour vivre. -Félix

-Magali, qui sourit à la vie...

Magali, artiste multidisciplinaire en arts visuels... un don de Dieu, instrument de Dieu... c'est pour moi viscéral de créer et de vous le partager. 


\section{APRÈS TANT ET TANT DE SIÈCLES}

Une histoire commence et recommence toujours cruellement par : Il était une fois dans la vie, mon p'tit gars, pour réussir, il faut savoir se battre.

Très jeune apprendre à se défendre.

Savoir se tenir debout et foncer droit devant

Combattre nos peurs

Jamais se laisser abattre.

Se donner un bon coup d'pied dans l'cul et marche au pas.

Il faut à tout prix s'armer pour affronter cette vie.

L'enfant-soldat en nous demeure apeuré

Bombardé de devoirs militaires.

Se creuse un abri

Oublie son paradis

L'enfer attaque toute une vie

lorsqu'on détruit

Là, ce que je suis

Battre ; s'armer ; se défendre ; se battre ; affronter

On nous mitraille de ces mots

Qui ne percent aucun mystère

Nous laissent que des courants d'air

Et j'ai peur dans le noir !

\section{$\underline{\text { Contes }}$}

CONTE (Magali)

Vivait en Afrique, au Sénégal, une très grosse femme avec un énorme cœur. C'est une bonté sur 2 pattes... c'est une artiste extraordinaire. Elle raconte à tout le monde que c'est un don de Dieu car elle n'a jamais pris de cours et pourtant, elle touche à diverses formes d'art et elle réussit des merveilles. Ce qui est bizarre c'est qu'elle croit que dans son gros ventre vit son enfant, une fille, qui naîtra un jour. Ce jour-là, elle libèrera l'enfant et sera enfin heureuse... Elle parle à son bébé à travers son ventre et les gens du village la croient folle... sauf sa meilleure amie Magali qui vit au Québec. Un jour, le sorcier du village lui enleva tout son surplus de poids par magie. Faudelle perdit son être car elle comprit que son enfant était imaginaire... Près de la folie, Faudelle déménagea au Québec, à Montréal. 3 ans sans carte pour vivre avec Magali. Ces 2 femmes n'avaient pas besoin de mots pour se comprendre car leurs âmes fusionnaient et leurs arts resplendissaient... Et puis paf! Magali tomba du lit, se réveilla brusquement sur le plancher. Elle prit conscience que ce n'était qu'un rêve cochon chien... tout un rêve ! 
CONTE (Félix)

27 avril 2012

Il était une fois un homme malheureux qui n'avait pas trouvé l'amour. Il le cherchait partout où il n'était pas. Dans les bars, dans le sexe, partout où il ne peut trouver que des illusions. Il est de plus en plus confus. Il ne veut plus parler à personne. Il est toujours seul et. de plus en plus, il s'enfonce dans la tristesse comme on perd une guerre contre soi-même.

\section{$\underline{\text { Je me suis regardée dans le miroir }}$}

\section{JE ME SUIS REGARDÉE DANS LE MIROIR, ET J'AI VU... (Ghislaine)}

Pour la $1^{\text {ère }}$ fois, j'ai vu l'artiste, celle que je ne croyais pas être.

Après tant d'années, je donne la permission à mon intérieur d'apprendre à connaître, de croire en tout se qui se cachait en moi. Je ne m'étais jamais définie comme artiste, peur qu'on me juge, peur de ne pas être à la hauteur du mot. Ce mot que je prononçais du bout des lettres, je l'attribuais largement aux autres. Jamais on ne m'avait donné la liberté de le sentir, de le vivre, de m'en servir comme bandage aux écorchures de la vie. Pourtant, le crayon ou le pinceau à la main me permet de plonger dans mon univers profond, là où se camouflait mon désarroi de vivre. Le merveilleux de ma création, je le voyais chez l'autre. Une juvénile, moi, j'étais de l'expression artistique. Si une de mes œuvres était appréciée, un malaise apparaissait, celui d'avoir réussi par «adon». Tout ce que je réussissais était un « adon».

J'adore aller gratter les blessures, scruter l'inconscient, descendre au plus profond de mon âme. J'ai réussi à faire surface. À chaque respiration je travaille à m'aimer. Même si je ne réussirai jamais à recréer le passé, je m'efforcerai à travailler à m'aimer peu importe les embûches, et ce tant que je ressuciterai de mes blessures.

\section{Lettres fictives}

\section{LETTRE FICTIVE À UNE AMOUREUSE (Félix)}

Je t'aime ô toi ma jolie. Je t'aime ô toi ma chérie. Je t'adore pour ta peau blême comme de la crème. Je veux passer ma vie trop courte avec toi pour que je possède les clefs de l'amour et que je vive heureux pour toujours. Tu m'aides à m'épanouir moi qui était une roche près de la mer et qui ne vivait que pour laisser passer le temps. 


\section{LETTRE À MOI-MEME (Lee)}

Montréal, 20 avril 2012

Lee, artiste en déroute

2012, Quelque part sur Terre

Au milieu de rien Pays Fou

C1K 1 K9

Chère toi qui es moi qui sommes nous,

Comment t'écrire ce que j'essaie de taire depuis 100 ans rien qu'en dimanches?

Comment te décrire ce cri qui croît en moi comme une mauvaise herbe, une racine du Diable qui s'entortille autour de mon arbre intime?

Comment t'avouer cette secrète souffrance sans user de mots stridents et de propos indécents?

Devrai-je encore dévêtir mon corps pour éviter d'avoir à mettre mon âme à nu ?

Devrai-je encore, sous les étoiles, interpréter les rythmes barbares de cette danse sacrée dont j'use et j'abuse pour invoquer les mânes qui m'ont précédée ?

Devrai-je peindre de couleurs criardes les chagrins de mon esprit fou ?

Combien de temps, de siècles encore, aurai-je à défoncer des tambours pour changer le beat de ma vie sans visage?

Devrai-je encore longtemps montrer, sur des écrans grisonnants, ma figure de style improvisée, grimaçant de ces hypocrites sourires qui maquillent l'abîme de mon cœur dévasté ?

Hein?

Réponds-moi, si tu le peux, le plus sincèrement possible...

Toi-même, qui t’aime

\section{LETTRE FICTIVE (Ghislaine)}

Pourquoi une lettre, pour ne pas que tu me lises distraitement sur ton I-pad. C'est bien son genre, diras-tu, c'est bien le tien, je me suis dit. L'encre sur le blanc de ma feuille, la spontanéité de l'élan de ma main, de l'élan de mon cœur. Ma sensibilité, je crois que c'est le côté de la personnalité qui t’a plu. Si tu avais su à quel point cela déragerait nos vies, tu aurais pris tes jambes à ton coup.

Je t'avais prévenu, même nos chemins séparés. Je garde ton ombre à mes côtés. 20 ans ensemble, c'est pas rien. 15 ans séparés, c'est trop.

Sans traces tangibles, je ne peux me convaincre combien notre amour était grand mais dans une boîte à souvenirs, j'ai retrouvé nos petits mots amour gagas qu'on se laissait sur la porte du frigo.

Quand nous avons décidé de nous unir pour la vie, et jusqu'à la mort nous serions fidèles, tu ignorais que nous entamions un parcours tourmenté, chacun en parallèle sur une corde raide. Tu me tenais encore la main pour ne pas que je tombe. Puis un jour tu l'as lâchée pour ton bien mais pas pour le mien. Pendant que tu continuais à avancer pas à pas, voilà que moi, je perdais pieds. Je n'avais pas compris la signification de tes silences. Tu n'as jamais prononcé «Je ne t'aime plus ». Jamais tu ne l'a avoué, mais ce fut plus difficile que de l'entendre. 
Mes états âmes, j'essayais de les cacher, mais toi tu les ressentais. L'amour fait rarement de compromis. Tu avais envie de respirer à plein poumons et moi je t'étouffais.

Aujourd'hui, un bonheur incommensurable nous réunit d'une certaine façon. Toi Papi, moi Mamie. Notre petite Dahlia chocolat au lait est le lien de notre ADN. Alors même si tu essais de le détacher, notre fille Chloé l'a rendu indénouable. ADN.

Ghislaine

\title{
Textes libres de poésie et de prose
}

(Félix)

Le bonheur

Je pense mais je vis

Je mens mais je prie

Je veux mais je ne suis pas persévérant

J'attends la fin mais je ne la précipite pas

Est-ce que j'ai assez de confiance en moi

Est-ce que je vais vivre ma vie jusqu'au bout

Est-ce que je vais vivre ma vie intensément

Est-il trop tard

Est-ce que je vais vivre ma vie sur le trottoir

9 mai 2012.

\section{DIS-LE MOI (Ghislaine)}

Engueule-moi, tue-moi de mots qui me perceront le cœur, vomis la hargne qui t'étouffe, te rend la vie dure. Frappe-moi d'insultes pour alléger ta détresse. N'épargne pas les mots que tu tais depuis tant d'années. Ma vie pèse sur la tienne, mes émotions t'emprisonnent dans un carcan de solitude. Je suis prête à affronter la colère de tes silences. Si tu ouvres la bouche, ne dis pas que tu ne m'aimes plus, mais assumes que tu me détestes. Ma folie a pris l'emprise sur ta vie.

\author{
AUTOPORTRAIT (Lee) \\ En fait, moi \\ La mère Lee, \\ Je suis listée \\ Presque neuve \\ Beau châssis \\ Carrosserie de luxe \\ Je carbure à l'octane des jours \\ Et à haut indice de puissance \\ Paraît même que je suis le moteur d'une génération... \\ L'arbre à came en tête \\ Et conduite impeccable
}


Je dirige ma transmission manuelle

D'une main ferme et rebelle

Malgré mon embraye haute vitesse

Et mon système à injection indéfinie

Je suis toujours cruise control

Tenue de route auto ajustable

Le volant sur la gauche

Système à décompression variable

Freins à disques intégrés

Jamais je ne dérape

Jamais je ne m'encrasse

Or, je tire ma performance

De mon cerveau direction

GPS et autres substances

Influencent ma traction

Habitacle super confortable

Coussins gonflables sur mesure

Pouvant stationner mes peurs et mes envies

Je suis le véhicule d'un avenir prometteur

Un seul défaut, cependant,

Mes gaz d'échappement...

(30-04-2012)

\section{LES YEUX DES PETITES FILLES, UN VOYAGE DANS LE MONDE D'ALICE AU PAYS DES MERVEILLES (Ghislaine)}

Les yeux des petites filles, ils sont bleus comme un ciel d'été, verts comme le printemps, bruns comme les noisettes. Si on y fige notre regard, c'est un envol sur un tapis magique jusqu'à la Caverne d'Ali Baba où se cachent des perles de rêves, des diamants d'innocence, de l'or en forme d'amour.

Les yeux des petites filles, des boîtes aux trésors sans clé. Sésame, ouvre-toi ! Sésame, dévoile tes rêves. Am stram gram pique pique colégramme, jeu de cachette pour découvrir leurs pensées. 5 sous pour connaître leurs rêves.

Les yeux des petites filles, mélancolie de mon enfance. 


\section{Michèle Vinet @ Les Impatients}

\section{Créations individuelles}

(Puncho Boy)

Un homme sérieux

En après-midi

Dans la paix

Et la joie

Rugueuse

Amère

Le parfum

Le travail

Et l'amour

Mouvement des yeux

En souvenir

De l'argent

Le respect

La gentillesse

Et la lumière du jour

Ils cachent quelque chose

De mon père

Le style de l'homme

Et son habillement

L'ANGE (Yacinta)

Dans la pénombre

Un bruissement d'ailes

Une odeur de vieux manuscrit

L'inconnu

Le désir et le ravissement

La peau

Couleur de miel

Éveil physique

Et divin

Lumière tamisée

Poussière d'or

Un homme

Une femme

Un silence

Un ange passe 
IMAGE (Siou)

La nuit

Vison de femme tourmentée

Des échos salins

Frisquet de bruit de ferraille

Transcende une chorégraphie

Vers un autre monde

Impasse d'un brouillard suspendu

Au loin

Rideau de glace

Où se fond une part de mystère

\author{
(Lee) \\ Saisis d'émoi \\ Les sages élèves \\ S'ébaubissent \\ Devant Sœur Lucie \\ Qui leur cause \\ Toiles de grands maîtres \\ Une araignée \\ Lui grugeant la cornette
}

\author{
(Gisèle) \\ Un matin \\ Un arbre dans la forêt \\ Ciel bleu \\ Paix et tranquillité \\ Nature exquise \\ Fluide \\ Les orages s'en viennent \\ Attendre la pluie \\ Le tonnerre \\ Les oiseaux sont partis
}

\author{
(Hanem) \\ Regard légèrement hagard et précis \\ Jaune, brun turc \\ Aucun espace temps \\ Couleurs cabane tranquillité \\ Le bruit du pinceau \\ De la spatule \\ Toucher l'épaisseur de la peinture \\ Manger la toile
}


L'odeur de la peinture à l'huile Atmosphère décontractée

Beauté

L'amour du beau

Un mouvement fluvial

Amoureuse du temps qui passe

Symbole de femme moderne

Lumière clarté

Les ombres illuminent

(Migicontée)

Miel d'amour

Femme voilée

Intrigue

Funestes fougères

Enterrement précaire

Chatoiement subtil

Mort rapide

Amourette interdite

Bruissement de vent

Impact équinoxial

Chuchotements

Sensualité

Trépas de rosée lilas

Meurtre anticipé

(Spino)

Visage féminin

Regard au loin

Entourage de lime et de citron

Arôme de thé vert

Douceur palpable de caramel

Baignant l'étendue

De jets d'eau matinaux 


\title{
Je bois un café
}

\author{
(Siou) \\ Les yeux affairés \\ Banquette au fond d'un café \\ Affaissé \\ Accroché à une tasse \\ Aromatique impasse \\ Ajout de sucre \\ Apaisement apprécié \\ Réconfort minuté \\ Un grand café \\ Un bon tranquillisant \\ Pour l'instant \\ Où tu ne te sens plus \\ Plus du tout \\ Malgré le flou \\ D'autres instants se corsent \\ Pour les buveurs de café \\ De la table d'à côté \\ (Puncho Boy) \\ Un jeune homme pensif \\ Confortable et heureux \\ Dans la nuit \\ Et la jouissance de la vie \\ Les conversations fusent \\ De tous côtés \\ La douceur et l'euphorie \\ La fête et le plaisir se terminent \\ En respirations amoureuses \\ Il est heureux \\ Même en l'absence d'une femme
}

\section{Beauté}

(Hanem)

La beauté du muscle cultivé

Grande littérature

L'encre du tatouage

Poétise le bras gauche 
Dans son mouvement mécanique

La moustache

Garniture virile

La symétrie de la ligne

L'éclat de la couleur

Du visage en action

Transcendance le l'imaginaire

La beauté véhiculée

Dans la fluidité

D'un simple geste

Une odeur d'accomplissement envoûte

L'industrialisation baigne

Dans la candeur

Et la subtilité

Le sang et la douleur ici ignorés.

(Siou)

Souvenir de printemps

Vent d'automne

Laisser aller

Entre chien et loup

L'émotion d'un espoir

Respiration profonde

Ronron du chat

Tic tac de l'horloge

Bzz Bzz de la mouche

Sur le dos

Dans toute son intimité

Apaisement

La fuite est rose

Mauve souvenir

(Gisèle)

Ma vie, une montagne dégradée

Un pas à la fois vers le rétablissement

La solitude, la paix

La nature, les oiseaux

Le son de mes pieds sur les pierres

Le moment présent

Respirer 


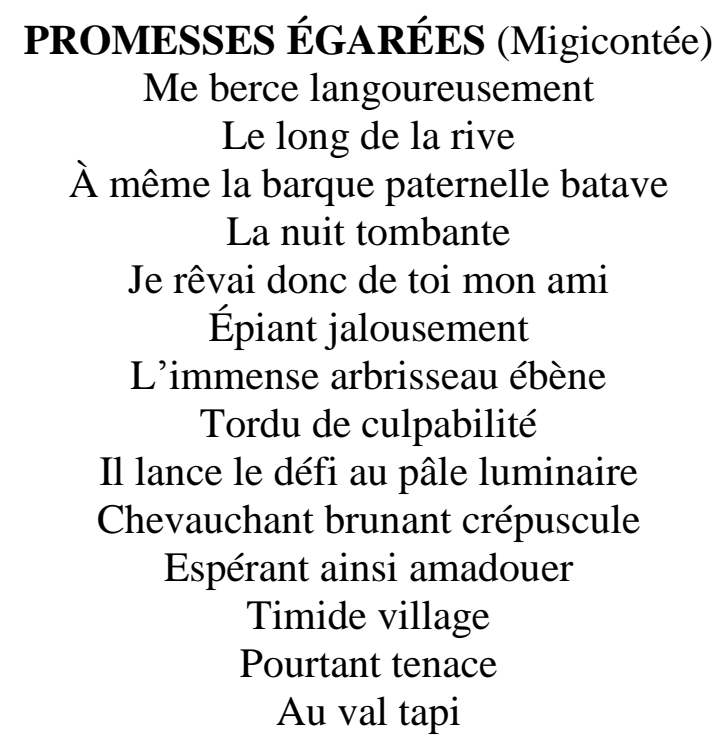

\section{Déconstruction et reconstruction}

Exercice collectif :

A) L'homme marche sur la rue

B) Orlando de la Plato, aux cheveux noir corbeau, habillé de cuir des pieds à la tête, fume un cigarillo dont les volutes s'échappent dans ses pensées. Il claudique, danseur de tango, vers son amour longtemps pleuré.

Exercices individuels :

(Spino)

A) Elle ne dort pas.

B) Son roman fut refusé. Recommencer l'inspiration écoulée. Comment réanimer le chant éraillé.

(Migicontée)

A) Cette personne qui se trouve dans la pièce est jolie.

B) Charlie, jeune homme immigrant et poli dans son langage comme dans son comportement, ne passe pas inaperçu dans le vaste corridor teinté d'or et de blanc. Ses cheveux d'encre noire lui donnent un éclat rebondissant. Il s'en trouve richement décoré. 
(Puncho Boy)

A) Ils se sentent seuls.

B) Les itinérants vivent dans l'exclusion sociale.

(Yacinta)

A) Une femme s'occupe de son enfant

B) Une jeune maman aux yeux attendris berce avec délicatesse son poupon bientôt endormi dans la douceur de la nuit.

(Gisèle)

A) Il attend.

B) Mon cher Samuel, jeune homme étudiant, sérieux, avec un gros sac de livres, vieille âme aux yeux brun foncé et centrés comme un laser, attend l'autobus. Les flocons de neige tombent sur ses épaules fortes qui tiennent le cœur et les problèmes du monde.

(Hanem)

A) La ville est bruyante.

B) La ville tambourine de mille pétards.

(Lee)

A) Une petite fille dort sur le côté gauche et semble faire un cauchemar sans fin.

B) Alice au pays des merveilles, le plumard étampé sur la joue gauche, rêve à l'ombre d'elle-même, espérant la lumière au bout du tunnel.

\section{$\underline{\text { Créations collectives }}$}

1

Trois fois charmé

Par la lumière

De ses yeux

Dansant

Sur la mer

Trois fois brûlé

Par le regard ébène 


De sa vie
Et la valse
De ses amours
2
Ce qui se cache
Derrière moi
Est devant moi
Dans les ombres
Incertaines
Mensongères
Et décrépites
Où se révèle
En pensée
Lyrique
Un passé
Qui refait surface
4
4
L'odeur du temps
Qui fuit
M'ensorcelle
Défaisant
Les toiles d'araignée
De mes pensées
Ainsi
Je reviens
Toujours
Vers toi
Mon amour
Insensé

\title{
Créations individuelles avec déclencheurs
}

\author{
(Siou) \\ Le brouillard \\ Tôt ou tard \\ S'infiltrera \\ Dans l'horloge de mon corps \\ Et le pendule \\ Qui traîne mon sort \\ S'amusera \\ À tard et à travers \\ À me cogner dans la tête
}


Des tic... tac... de mémoire

Où l'oubli est en foire

\author{
(Spino) \\ Sucré velours \\ Le premier comme friandise \\ Le second en habit de sortie \\ Bonbons, chocolats et crème glacée \\ Retroussant l'âge de mes années \\ Couleur royale et noire \\ De satin blanc \\ Douces images de mes quinze ans \\ Qui chantent gaiement \\ Des quintessences quasi enterrées \\ (Yacinta) \\ Au bout de mes tourments ronchonnant \\ Grimaces hargneuses \\ Point enfin la délivrance \\ En une expiration bienfaisante \\ Les fleurs odorantes, les couleurs vives \\ M'habitent d'une humeur exaltée \\ Revigorée
}

\title{
$\underline{\text { Sucré velours }}$
}

(Hanem)

Le velours de tes dents

Sucrées, chaud baiser

Carrée de velours

En un rythme sourd

S'échappe l'émotion

Du sucré velours

J'accours, je dévore

Et j'emmagasine

Le courant du temps

Du moment présent

Une dent contre moi

Et flotte le courant

Baiser chaleur sucré velouté 
Grande volonté

Bien vouloir

Servir le thé

La cage de mes émotions défoncée

\author{
(Spino) \\ Il est au bout \\ Et pourtant toujours là \\ Personne derrière le secondant \\ Un appel incessant \\ Me dit de lui : plus jamais \\ Son visage carrément défait \\ $\mathrm{Ne}$ reviendra te visiter \\ Sans l'ombre d'un doute \\ La fin est arrivée \\ Et grand l'oubli de son corps
}

(Yacinta)

Sucré velours ta bouche vermeille

Se dépose sur ma joue

Interrompt mes rêves endormis

Il est déjà midi

Et de cette délicatesse

Naît un autre jour exquis

(Gisèle)

Sucré velours

Doux comme le satin

Réduit la richesse

D'une journée à longue durée

Ravissement

Velours valeur

Goûter au sucre du succès

(Puncho Boy)

Au bout de mes lèvres charnues

Il y a les cicatrices

De mon âme luisante

Come une petite toile

Tissée sur une armure 
En route vers des chemins égarés

Solstice de mai

Menu repos

Pour des gestes calmés

Par la tempête de mes draps

Tachés par des lettres enrhumées

(Migicontée)

Sucré velours

Au fil des jours

Détonne du ton mièvre

Jadis soutenu

Par des discours controuvés

Tes parfums de par trop étrangers

Reviens-moi

Enraciné et refleuri

De tes senteurs propres

Récréatives et rajeunies

Que j'aimais

(Siou)

Sucré velours

De tes contours

Qui se dessinent

Magiques

Sur du papier glacé

Gardé en privé

Je n'ose te regarder

Et déchirer l'âme

De tes souvenirs

Tu n'es devenue

Que rature

Pour mes poèmes futurs

(Lee)

L'odeur sucrée

De tes lèvres velours

Impriment sur ma joue

Des souvenirs tenaces

Qui renaissent chaque fois

Que je t'embrasse

Amour feu

Amour vie

Amour toujours 


\author{
(Puncho Boy) \\ Sucré velours de mon pas \\ Des ronrons de mon chat \\ Des chances de mon cas \\ Des fruits de ma lâcheté \\ De mon lit en catimini \\ Des mâts de mon puits \\ Des nuits castrées de mes ruines \\ Les chapitres de mon histoire \\ Ruminent entre les vaches laitières \\ Dans la campagne frustrée \\ De mon enfance \\ (Lee) \\ Brouillard éphémère \\ De mon âme égarée \\ Qui s'engorge d'émoi \\ Sur mes rêves lovés \\ Détournant de mon être \\ Le voile vérité \\ Qui recouvre en 3-D \\ L'image projetée \\ Sur mon iris rêveur \\ Et j'incendie d'amour \\ Les étoiles miroirs \\ Offrant à tous vents \\ Des effluves d'espoir
}

\title{
Créations individuelles
}

\section{POÉSIE (Lee)}

Poésie,

Tout comme miel,

Distille une odeur

Qui court dans l'air

Et s'accroche à mon nez

J'en aspire une ligne, Une strophe, un verset Et voilà que mon âme

Se change en une fleur

Dont le précieux pollen Libéré de mon cœur

Dépose en ma tête

Un bouquet de pensées 


\section{DÉFILÉ DE MOTS (Hanem)}

Un torrent de mots en mon cerveau

Les mots autoroutes de mon cerveau

Passe, passe, repasse, dépasse

La vitesse permise du temps présent

Un tapis de pensée enveloppe mon cerveau

Déclare que tout est faux

Siècle de plastique et de rebuts

Philosophie fausse du Grand Zéro

Fatigue, spleen, down, pensées recyclées

Léger dérèglement de mon instrument

J'accorde la tension de mon encéphale

La musique de ma tête danse le Rock

Je reprends le flot de mes mots

Un kiosque à l'épicerie Métro

Je vends des mots au gramme, à la livre, au kilo

Quelques rares clients s'approchent

Je cultive les mots en pots

Et à nouveau tout est faux

Ajustage constant de la tension de mon esprit

Une journée s'achève vers le bas

Sommeil réparateur, pensées douces et sans friction

L'impossible à accomplir, un voyage sur la lune

J'ai apprivoisé la circonvolution de ma raison

Depuis, l'horticulture de mes pensées croît à vitesse normale

Vitesse permise et temps présent

\section{GABARDINE OU LE RÊVE INVENTÉ (Lee)}

Hélas, mon cœur n'est plus qu'un vieux mélange amer

D’une joute éperdue entre vous et ma mère.

Car j'ai encore en tête, divine gabardine,

Les victoires et défaites que vous avez livrées en sourdine

Ma mère et vous, gaine, en des combats curieux ;

Comme des mandarines sur mon fief, sur mes vœux.

Vous m'avez arrachée, d'une à l'autre, comme précieux tissu Jusqu'à ce que je sursaute et me soustraie à vos vues 
Je jure, ni mère ni vous n'aurez raison de moi

Car je suis l'archifou visité par l'émoi

Des muses affolantes

D'un bien triste poème

Que j'enferme, démentes, en ma face de carême

Ô belle de ma vie ! ne prêtez point espoir

Si noire est ma nuit, si vain mon savoir

Que je ne saurais dire les aveux qui me pressent

Sans flancher ni m'ouvrir aux dieux qui me blessent

Alors, je vous avoue enfin sans honte aucune

Vous êtes, de mes atouts, la plus belle fortune

Et si désespéré, je devais dépérir

D'avoir avoué mon si tendre délire

Veuillez me pardonner et gardez souvenir

De qui vous a aimé jusqu'à en mourir

OUBLI (Hanem)

J'ai déposé mon cœur dans la poubelle

Sa faculté d'oubli s'amplifie

La performance un must aujourd'hui

Je perds le fil du courant

Je m'étends sur mon lit

Réfléchis à l'espace temps de ma vie

Dresse un long bilan sans ornements

Peu d'accomplissements: un petit tiroir

Je suis en sueur, j'ai peur d'ouvrir ce tiroir

Je suis incapable d'épingler la réalité

Elle fuit comme un brigand vigilant

Comment ferais-je ?

J'ai froid, je grelotte, je claque des dents et je pleure

Soudain je ne sais pas par quelle magie le tiroir s'ouvre

J'entends la musique des Beatles, Yesterday

Une ballerine tourne et danse

Le coffre aux trésors de ma jeunesse

La ballerine s'adresse à moi et me dit:

« Pour le Grand Eil

Seuls les accomplissements du cœur comptent »

Je saute du lit et tourne, tourne, tourne

Je m'affaisse sur mon lit étourdie

J'ai une mine d'or d'accomplissements du cœur

Ma vie, consacrée au labeur des cœurs

Hé, là !

N'oublie pas tous ces cœurs qui t'adorent 
POST-POST-NEW-NEW (Lee)

Je me conjugue

Aux pétillantes

Hérésies fluides

Tout en lénifiant

L'espace grandiose

Et métallique

De ce verset

Strophistiqué

Et j'avais l'élixir

Malin des cryptogrammes

De ce poème nirvanique

Qui s'enroule d'existence

Cochléaire

Et la voracité post-post-new-new

Stratifie ces vers

Irradiés de gaz moutarde

La main implacable

Et la fortune sourcilière

J'arrose mes platanes violacés

À saveur parmesane

Aspirant les reliques bavures

De ces rimes émancipées

La poésie fout l'camp !

\section{$\underline{\text { Nouvelles }}$}

\section{ÉPIPHANIE (Migicontée)}

Il vacillait à cette table, chancelant non pas d'hésitation, mais de crainte pour sa suite. Où étaient-ils donc tous passés ? L’endroit convenu leur aurait-il échappé ?

Ce ne serait guère la première fois que la foi leur faisait défaut. Pourtant, la guerre s'annonçait en haillons vêtant gauchement les gendarmes sournois l'ayant épiée dès son arrivée.

Sa mère, l'œil perçant, le cœur toujours vaillant, semblait essuyer la table. Grâce au sort, lui indiquait la triste suite arrivant dans la ruelle avoisinante... Finalement !

L'ombre de sa frangine précurseure se démarqua du chahut des suivants entremêlés de sbires désormais alertés. 
Pourvu que la prophétie soit annoncée, qu'importe leur fin. Il fallait que lui seul ait voix.

Les étoiles se taisaient.

\section{FEMMES AU BALCON ; TOUT BLEU (Spino)}

Une grande dame assise regarde au loin. Le ciel bleu, au fond, au-dessus de l'eau, une mer ballottant des petits voiliers. Huguette se situe tout près, visuellement, à côté d'arbres verts, en compagnie de celle qui compte dans sa vie, sa mère. La fille se soucie de son confort à chaque instant. Assise non loin l'une de l'autre, elles admirent la Seine.

La cuisinière aura préparé le repas de dix-neuf heures. Ensuite elles iront au théâtre du quartier. Huguette a tout prévu pour une soirée à trois. En attendant, l'air est merveilleux et annonce du plaisir pour la suite. Sur le bout de sa chaise, Huguette est prête à bondir. Jean-Pierre viendra la délivrer assurément.

Le téléphone ne sonne pas. L'heure avance. Décontenancée, elle ne laisse rien deviner à sa mère malgré l'environnement rempli de douceur et bleuté. Son être intérieur se noie dans l'inquiétude. Il ne sera pas à temps pour la dernière représentation qu'elle a eu du mal à réserver.

Sa vie est marquée par l'ennui. Les heures ont glissé par la fenêtre quoiqu'elles offrent de jolis panoramas. Durant cette attente, elle révise des pans de sa vie. Elle se retrouve seule avec elle-même, sans enfants, confinée à une existence sauvage. Ces deux êtres, sa mère et celui qui viendra sans doute dans un bref instant, sont son univers journalier.

Toutefois, le jeu de scène l'intéresse. La porte d'entrée s'ouvre. Jean-Pierre, tout heureux, s'approche des deux femmes. Huguette cesse son tourment et lui rend son sourire éclatant.

Comme bien des spectateurs, ils forment une famille unie, au moins aux yeux de l'héroïne. La nuit bleutée arrache les joies.

\section{LA LUNE (Puncho Boy)}

Jean-François regarde la lune, belle, joyeuse, immortelle dans le ciel. Jean-François est chauve. Il va à l'église pendant que le soleil rayonne et éblouit les environs. Le jour et la nuit se succèdent sur la planète terre dans la galaxie. Le soleil est couché, l'ambiance est à la fête. Le feu et la lumière ne sont pas dans le haut d'une ville où les gens sont à l'église. Le soleil tourne autour de nous, la tête d'une belle fille heureuse me vient à l'esprit pendant que je regarde la tour Eiffel. Je ne participe pas aux messes à l'église pendant que la succession des jours et des nuits anime la vie sociale.

Moi, je ne parle pas aux autres. 


\section{L'ÉQUILIBRE PRÉCAIRE : Extrait (Lee)}

Quel choc ! Elle est si bouleversée qu'elle tomberait à la renverse si ce n'était son sens inné de l'équilibre précaire. D'ailleurs, elle a toujours vécu sur le fil de fer de la traverse océanique des malheurs. Elle a fini pas s'en accommoder.

Mais ça, c'est arrivé trop vite. Habituellement, elle contrôle mieux ses « voyages ». Mais ça n'a tellement rien à voir avec ses habituelles séances en lesquelles elle s'offre un billet pour nulle part : un aller-retour pour une personne, à tarif réduit pour classe économiquement faible.

Début août, jour de semaine, 15:30 h. Florence sort de l'Accueil Bonneau où elle vient d'avaler un copieux dîner. Bras en croix, comme pour offrir son corps au soleil, elle se dirige tranquillement vers son refuge habituel : cette église située à l'angle de deux artères coronariennes de Montréal, l'église Notre-Dame des quarante douleurs ! Endroit idéal pour roupiller. Le curé est cool, il la laisse se promener dans les allées, parler aux statues, ronfler à tout rompre et faire son Chemin de croix à l'envers. Que voulez-vous, ça l'encourage, la Florence, de voir qu'au fil des stations, le Christ prend du mieux !

Il sait bien, le Père Fouquet, qu'elle n'est pas méchante, la Florence. Un peu perdue, certes, mais pas méchante. Perdue, encore faut-il s'entendre sur ce mot. Car Florence connait par cœur toutes les rues, ruelles et recoins de la métropole. Pour quelqu'un de perdu, c'est plutôt bien.

Aujourd'hui. Pas question que la séance dure plus de dix minutes. Promesse de Florence. La sollicitation n'a pas rapporté cet avant-midi, Il faut donc être à temps sur le parvis pour arnaquer les dévots de la messe de 17:00h. Compris, Florence? De la dis-cipli-ne!

Elle en est là dans ses pensées quand $\boldsymbol{C} \boldsymbol{A}$ est arrivé...

\section{HANNAH ET RODRIGUEZ : Extrait (Yacinta)}

Petit matin de taffetas aux effluves légers de patchouli. C'est le début de l'été sous le ciel gris d'Istanboul où retentit la prière musulmane.

Panorama sur tons de vert juxtaposés, fraîcheur et espoir quotidiennement renouvelés. Une fente dans la Terre reverdie, profonde comme une falaise, sépare ce coin de ville aux maisons vertes coquettes d'un château vert lui aussi. À perte de vue, l'herbe perlée de rosée, des arbres au feuillage verdoyant, flanqués d'oiseaux qui chantent et les voix des marchands qui installent plus loin leurs échoppes. Revoilà la nature et la cité en éveil.

Rodriguez, beau tsigane, fort de ses cinquante ans et de son corps bien découpé à la mâchoire virile, arbore une chevelure de jais. Ses sourcils, tout aussi noirs, dépassent ses arcades et forment un trait au-dessus de son nez dévoilant un caractère impétueux et jaloux.

Sa cousine, Hannah, âgée de trente-huit ans, belle bohémienne aux traits volontaires, à la peau mate et aux cheveux foncés, dégage, elle aussi, une force de caractère.

Sur une nappe rouge garnie de fleurs, repose une carafe de vin rouge. Hannah et Rodriguez boivent à la même coupe. À l'arrière se détache une mosquée de granit. 
Le couple a fui le campement Rom en Bulgarie pour vivre en toute liberté leur secret intime. Hannah est enceinte, elle qui, jusqu'à ce jour, se croyait stérile.

À l'insécurité du lendemain, supplée une passion puissante qui les unit. Sur le rouge intense de leur amour s'appose une touche rose tendre d'insouciance et de confiance.

\section{POUR SES LENDEMAINS (Siou)}

Pour ses lendemains, il s'est mis en tête qu'il n'aurait plus jamais besoin de réveil matin. Il ne se laissera plus jamais prendre par le sommeil.

Ce manipulateur brouille les heures avec ses pétarades d'images passées au tordeur.

Au début, on nous détecte une certaine habileté à cogner des clous, puis sans plus tarder, le tourbillon nous embarque dans un travail au noir, à n'en plus finir...

Se leurre ainsi notre subconscient ne sachant plus démêler

le rêve du réel

le réel du rêve

Et le rêve du réel commence, s'activant à casser les heures du cadran, s'éclairant une suite dans ses idées.

Il décide enfin de jeter le lit par la fenêtre, déchire son pyjama en guenille, donne son oreiller au chat, baille profondément une dernière fois et, pour clore le cycle dodo, métro, boulot, s'étire intensément, de long en large, sur toute la superficie de sa défunte chambre à coucher.

Enfin, pour une toute première fois, le passé simple ne passera plus devant chez lui.

Lui, en marche

droit devant

droit debout

Et non plus à genoux devant les rêves à réaliser à tout prix. Maintenant, plus jamais il ne dira : «je t'en prie ! »

\section{SONGE EN ROUGE (Hanem)}

Un tableau de Zilon, galerie Lounge TD, Maison du festival, rue Sainte-Catherine à Montréal. Zïlon peint en rouge et noir presque uniquement.

Je plonge dans le rouge du tableau et tombe dans un nuage vaporeux. Nous sommes à Evain en Abitibi et mon amie Nicole et moi avons sept ans à l'époque. Les odeurs estivales et leurs parfums dansent en farandoles. Un court été tout en plaisir s'annonce. Dans mon songe, j'entends une sirène ; c'est le jour où le frère de Nicole, Raynald, a perdu la vie, à neuf ans. Par une belle journée d'hiver, il glissait sur la côte et il a été écrasé par un camion. Ce camion transportait des résidus de roches de la mine Elder, une mine d'or, située à quelques kilomètres du village. Suite à cet événement, les parents nous ont interdit de glisser sur la côte.

Je revois Nicole avec ses petites balles rouges et je n'arrive pas à comprendre le pourquoi de cette scène. Mon panorama cinématographique se déroule et Nicole ramasse des 
petites fraises des champs d'un rouge cadmium éblouissant. Je m'empresse de la rejoindre et je l'aide à remplir son petit panier. Sa mère en fera des confitures pour l'hiver. Maintenant, nous ramassons des noisettes sur la petite montagne à Boisvert. Dans mon songe, les noisettes sont rouge écarlate. Nous n'avons aucun gant pour les ramasser. Nous avons les doigts remplis de minuscules piquants, mais nous causons et, arrivées à la maison, nous plongerons les mains dans l'eau glacée pour nous en départir.

Nos activités estivales sont multiples, nous trouvons toujours un jeu pour nous amuser ou nous en inventons un. Le bonheur et le plaisir font partie de nos jeux.

Soudain un nuage rouge clair entoure nos activités. Je me souviens du jour où nous avons inventé le jeu du magasin de roches. Nous ne savions pas à quoi jouer, mais nous avons trouvé. Notre cour avant était tapissée de roches de pyrite qui ressemblaient à de l'or. Nous avons sélectionné dix roches chacune. Nous faisions des échanges en considérant la quantité de pyrite de chaque roche. Parfois, un échange pouvait se solder par deux roches pour une. Ce jeu se déroulait dans la réflexion et le sérieux. Un nuage rouge soutenu flotte au-dessus de notre jeu.

Tout à coup, Nicole saute dans un amas de petites balles rouges et rit à en perdre haleine. Subitement, une pluie d'osselets se met à tomber. Nicole s'enfonce sous les balles. Elle sort de l'amas et se déblaie un petit carré, lance la balle rouge en l'air et ramasse les osselets un à un. Le jeu d'osselets et la petite balle rouge, notre jeu préféré. Tant de plaisir.

Mon nuage rouge Zïlon se dissipe et je suis debout dans la galerie Lounge TD. Aujourd'hui, j'ai perdu mon amie Nicole. L'éloignement, les années et la distance. Toutefois, je conserve la saveur et la joie de nos jeux simples et créatifs.

Souvenirs d'enfant. Confort moelleux du présent.

\section{$\underline{\text { Jeux d'improvisation }}$}

\section{LA MUSIQUE DES YEUX (Puncho Boy)}

Je lui donne un goût amer

Tout au creux de la mer

Vide au fond du cri

Miner par le bruit

Avance tout petit

Comme un son

Mélangé

Par les couleurs vertes 
SANS ABSOLUS (Siou)

Je bois des jours de neige

Où le chauffage

N'a pas tenu le coup

Mes sentiments se figent

Des glaçons dans mon pantalon

J'avale mes déraisons

L'ABSENCE (Yacinta)

Le manque de sous

De tendresse

D'écoute

De caresses

De mémoire

Cette peur

De l'absence absolue

Du néant

LE BALUCHON DE TOUT ESPOIR (Spino)

On le promène

Chaque jour

Un enfant le traîne

À chaque porte

Chantant ton nom

Un si bel espoir

Bleu et rouge tricoté

Marchandant la pièce d'or

Sachant gaiement le vide

Sa balançant au fond de tout

LE SOUFFLE RETENU (Hanem)

J'ai cru que j'allais mourir

L'émotion mordante

Le pouls titillant

Le souffle coupé

Cet événement

Me troublera

Toute ma vie

La mort en une seconde

Une Joconde s'effrite

Fish and Chips 
COMME UN VENDREDI (Puncho Boy)

Comme un vendredi

Je chevauche

Un fer mélangé

À la pierre

Qui finit en rivière

Et va battre une crinière

Qui bouge

Sur la rizière glacée

Au fond d'un rêve

Menacé

LA MER (Yacinta)

La mer

Océan de perles

Dévoreuse de marins hagards

S'engouffrant dans la tempête

Restitue sur la plage

Ce qu'elle a englouti

Pendant la nuit

Retenant en son sein

Cadavres et trésors disparus

Sous ses lames d'argent

CE QUI HURLE (Siou)

Tout est silence

Pour une fois

Pour une fois

Je me sens riche

Je peux tout dépenser

En un éclair

Même mon énergie

Mais je reste assis

Immobile

L'argent peut bien

Me brûler les doigts

Tant et tant

Ce qui hurle en moi

C'est toi 
NUIT D'ÉMERAUDE (Hanem)

Brille l'Irlande verte

Un pays de gazon

Un farfadet au tournant

L'écriture de Joyce et de Beckett

Toutes les routes

Ont leur écriture

Tous les pubs respirent

La joie de vivre

Et la Guinness

Une culture colorée

Un sens du civisme éclaté

Ma mère a adoré

Ce pays vert

Plus j'y pense

Plus je veux retourner

En Irlande

SANS SUITE (Spino)

Mon voyage a pris fin

Je ne suis plus là

Un autre projet arrive

Il ensevelit

Ce qui fut nous deux

Une suite sans fin

Active en moi

Le souvenir

Et pourchasse

Le chemin

Emprunté déjà

PETIT BOUT DE GUÉRISON (Puncho Boy)

Comme un petit bout

De guérison

Je ravage et dégage

J'avale

Comme une truite

Gonflée à bloc

De marbre

Qui partage

Ses biens

Ses gains

Fortuits et forfaitaires

De richesses infinies 
MACADAM INTÉRIEUR (Yacinta)

Quand mon cœur se glace

Que mes pensées sont de pierres

Que mes traits se figent

Que mes gestes sont brusques

Que mes pas sont lourds

Et saccadés

Je marche sur mon macadam

Intérieur

Pas question que je trébuche

Entêtée

Orgueilleuse

Et enragée

ROUGE AMOUR (Spino)

Quand on est en amour

On voit rouge

Sinon c'est bleu

Contraste de température

Lorsque je te vois

Mon être respire

Rouge

Et mon cœur

Mon amour

Danse dans les yeux

Toutes flammes lancées

\section{L'OISEAU BRÛLANT (Hanem)}

L'oiseau brûlant

Qui frappe à ma fenêtre

Oiseau-homme

Ou homme-oiseau

Ce qu'il faut

Pour dérider

Une soirée

L'imaginaire

Sollicité

Et embrumé

Est-ce un amant qui frappe

Ou un oiseau

Je le saurai bientôt 


\author{
J'ouvre la fenêtre \\ Et voilà \\ Une surprise \\ Grandeur d'homme \\ Qui se cache \\ Sous le déguisement \\ Un amant d'antan \\ Et c'est la fin du monde \\ Que ferais-je \\ Aujourd'hui \\ De cette vieille peau? \\ Le jeter aux ordures!
}

\title{
Sylvie Frigon@ La rue des Femmes
}

La rue des Femmes est un organisme à but non-lucratif aidant les femmes en situation d'itinérance et de grande difficulté à s'en sortir. Ainsi, une gamme de services sont accessibles, de même que des activités où l'art et l'art-thérapie agissent à titre de catharsis et d' « issue de secours ».

www.laruedesfemmes.org

(Jackie)

Qu'est-ce qui me représente !...

«La Perfectionniste »

Au plus parfait !....

1-Difficulté à déléguer, je préfère le faire moi-même !...

2-Soucieuse du détail !...

3-J'aime que tout soit fait à ma façon à moi !...

4-Territoriale, j'aime que mon environnement où je vis soit bien entretenu !.. Sinon, ça m'énerve !...

5-Difficulté à accepter les erreurs que je fais !....

6-Difficulté à accepter les imperfections de mon corps et le surplus de poids !...et je préfère être seule... je me prive d'être en couple à cause de ça...

7-Orgueilleuse comme un paon !... Important de bien agencer les couleurs des vêtements que je porte !...

8-Discipliné, ordonné, méthodique, j'aime que tout soit à l'ordre dans l'espace où je vis !....

9-J'aime être à l'heure lorsqu'on me fixe un rendez-vous !... c'est réciproque lorsque je fixe un rendez-vous à un autre personne !... 
10-Dur avec moi-même, je manque de flexibilité et aussi très exigeante avec moimême !...

11-J'ai un profil très militaire !...cela doit-être dans mes gènes transmis par mon père et ma mère !...car ma mère étant jeune a été dans l'armée de l'air....et mon père dans la marine !... et c'est ce qu'il (elle) m’ont transmis comme éducation !....

«Ma mère me répétait souvent cette phrase »

« Ma fille, tu dois savoir et apprendre dans la vie »

Jackie!

Bizou ! Xxx

\section{Poème collectif}

(Milana, Jackie, Carlie)

1-J'ai mal à ma mère. Noirceur. Absence. Froideur. Tout ce qui me fait peur. Intolérance. Pourquoi ? Je t'ai cherchée en vain. Orpheline de toi. Bloc de glace ! Ode à ma mère : sécurité, bisous, toucher, réconfortant, protection, amour, tendresse, caresse. J'ai mal à ma mère : -détestable -méchante -arrogante - clarté/noirceur -absence -intouchable chaleur humaine -froide perfection - distante - incompréhension - ambigüité - rôle ingrat - ingratitude - « gendarme à culotte »

\section{Je me suis regardée dans le miroir et j’ai vu...}

\section{JE ME SUIS REGARDÉE DANS LE MIROIR... ET JE VOIS.}

Cher miroir. Je suis la personne qui t'a fait beaucoup de misère en te faisant la guerre, je t'ai boudé, et même négligé pendant plusieur années.

Mais aujourd'hui, je te remercie de ne pas me tenir rancœur parce qu'un beau matin, je me suis vraiment arrêtée et tu m'as fait voir le bonheur, la joie et la paix que je cachais au fond de moi.

Aujourd'hui, je fais en sorte que tu sois l'objet le plus précieux pour moi. Plus jamais je vais te tourner le dos. Maintenant je sais que je peux parler avec la femme qui apparait en toi. Je sais que je ne suis pas une belle femme, mais j'ai encore beaucoup de choses à découvrir qui sont cachées au fond de moi.

Merci, cher miroir d'avoir été patient avec moi.

A bientôt, mon cher miroir, on se parle de plus en plus et plus jamais je vais t'oublier. Et avec toi je me sens belle quand je me regarde en toi. 
JE ME SUIS REGARDÉE DANS LE MIROIR ET JE VOIS... (Milana)

D'abord et avant tout une femme vieillissante qui, constamment, s'est laissé définir par autrui. C'est ainsi que je me suis perdue dans les méandres des mondes intérieurs de mes proches qui croyaient savoir mieux que moi-même qui j'étais, qui je suis et même qui je serai. Finalement, au fil de mes lectures, j'ai réalisé qu'en agissant ainsi, ils me parlaient d'eux. En effet, lorsque l'on juge autrui, en réalité, on est en train de se définir soi-même, de dire aux autres comment on est, qui on est et quelles croyances on porte à l'intérieur de soi. Bref, en plus de nos croyances, nous étalons nos préjugés, nos limitations, nos blessures, nos incompréhensions, nos peurs, etc. Donc, dorénavant forte de cette connaissance, je serai en mesure de faire la part des choses, d'accepter ce qui m'appartient et de remettre à autrui ce qui leur revient de droit. Ainsi, mon bagage sera plus léger de même que le leur s'ils décident de faire la même chose.

Je vois une femme déçue des attentes qu'elle nourrissait envers ses proches. Alors, au lieu d'attendre d'être reconnue par eux pour ce qu'elle est réellement, il serait plus judicieux qu'elle apprenne à être totalement elle-même plutôt que d'être le miroitement de leurs jugements à son égard. D'ailleurs, en continuant d'être le reflet de leurs jugements, elle ne les aide aucunement à se connaître et à la connaître. De plus, en adoptant un tel comportement, elle se nuit personnellement.

Je vois une femme qui s'est laissé insulter, humilier, bafouer, battre et presque tuer parce qu'elle avait peur de dévoiler ses sentiments, ses émotions, ses sentis et ressentis, car on lui avait faire accroire, tout au long de sa vie, qu'elle était incapable d'évaluer correctement une situation, un événement, un vécu, supposément à cause de sa trop grande sensibilité qui lui faisait voir les choses autrement que ce qu'elles étaient dans la réalité. Bien sûr, en partant de là, il n'y a qu'un pas à franchir pour sombrer dans le déni de soi, le manque de confiance en soi, le doute endémique, la dévalorisation, l'autosabotage et l'autodestruction. Ce que, bien entendu, elle a fait jusqu'à tout récemment, c'est-à-dire jusqu'à son passage obligé à la Rue des Femmes.

Je vois une femme brisée, échouée sur les écueils de sa vie et qui a sombré sous le lourd fardeau imposé par ceux que, pourtant, elle aime tant. Longtemps, elle a ballotté sur les flots tumultueux d'une mer orageuse en s'agrippant, de temps à autre, sur les récits chimériques de lieux utopiques chargés de parfum d'encens évoquant une possible trève. Pourtant, il en a été tout autrement ! À chaque fois, elle vécut d'amères déceptions la laissant nue et désemparée sur la berge, attendant inlassablement que le ressac de la mer déchaînée l'entraîne sur des rivages moins rocailleux. Souvent, elle caressait l'espoir qu'un jour nouveau se lèverait et verrait se poindre à l'horizon la terre promise tant attendue qu'elle habiterait enfin libre de toutes entraves.

Durant des lustres, dans ce naufrage, elle a surnagé au-dessus des flots aussi longtemps que ses forces, autant physiques que psychiques, le lui ont permis. Une nuit, elle a coulé corps et âme dans les profondeurs cadavériques du coma diabétique. A son réveil, elle comprit que son corps tirait sa révérence et abdiquait devant son impuissance à contrôler les éléments abyssaux. Alors, de guerre lasse, elle lui octroya un répit, afin qu'il puisse reconstituer ses forces et reprendre son odyssée inachevée. 
Après de multiples tempêtes de cœur hivernales, voilà que, soudainement, le soleil se leva et réchauffa sa peau, éclairant d'une connaissance nouvelle les cicatrices qu'elle cachait si bien dans le secret de son âme. Enfin, en osant se dévoiler, ses blessures cristallisées dans le corail se brisèrent d'elles-mêmes sur les récits d'anciens paradigmes devenus désormais désuets. La force de vie prit dès lors l'assaut d'une nouvelle vague déferlante remplie de promesses réjouissantes qui chantèrent leur allégresse d'être libérées du joug d'un carcan emprisonnant, étouffant, empoisonnant, en entonnant : « $\mathrm{Ne}$ tuons pas la beauté du monde », ni la nôtre.

Il y aurait tant à dire encore, mais à quoi bon, puisque désormais je surfe sur une nouvelle vague, un autre courant d'espoir, vers un nouveau paradigme qui m'amènera vers d'autres horizons, de nouveaux défis et de nombreux écueils encore, mais en comprenant que le creux de la vague recèle en lui la crête de la vague.

Voilà comment le peintre dessine le canevas de sa vie : de creux en crête et de crête en creux dans toutes les nuances de sa palette de couleurs. Il ne peut en être autrement, car c'est ainsi que la vie nous dévoile à nous-même nos forces et nos faiblesses, afin que notre devenir glorieux se sculpte au gré des saisons de notre vie, de vie en vie.

En dernier lieu, je vois une femme qui s'adresse à elle-même des encouragements et des prescriptions de vie pour réveiller en elle le courage de s'accomplir, de s'assumer et de reprendre sa route d'un pas allègre.

\author{
JE ME SUIS REGARDÉE DANS LE MIROIR ET JE VOIS \\ -une nouvelle femme. \\ -une grand-mère heureuse. \\ -je vois grandir mes petits-enfants \\ -je vois une vie nouvelle \\ -je vois que je veux bien entretenir cela autour de moi.
}

\title{
LE MIROIR (Jackie)
}

Je me suis regardée dans le miroir, et je vois...

1-Des yeux tristes !...

2-Des symboles de vieillissement !...

3-Qui se sont vus sans maquillage !...

4-Qui est indécise !...songeuse...

5-Qui est épuisée !...fatiguée !...

6-Qui est au bout de son rouleau !...

7-Bombe à retardement !...

8-Une femme qui a peur du changement !...

9-Une femme qui a peur de l'inconnu !... 
JE ME SUIS REGARDÉE DANS LE MIROIR ET JE VOIS... (Gisèle)

Que mon visage amincit, amaigri, fatigué, mais je vois aussi une femme belle avec des yeux marrons et quand elle sourit, personne ne peut y résister.

\section{Lettres fictives}

\section{LETTRE À SOI (Jackie)}

Heure : $3: 26$ p.m. Jeudi le 12 avril 2012

Cette lettre s'adresse à moi-même, la femme adulte de 64 ans.

Comme je me connais, je suis une femme très insécure qui a toujours besoin d'être rassurée, sinon j'ai tendance à paniquer, à faire de l'angoisse. Je deviens anxieuse et nerveuse, et mon réflexe est de vouloir tout abandonner.....

La démarche que tu es en train d'entreprendre, dis-toi bien que c'est tout à fait normal que tu aies des hauts et des bas, que tu te sentes destabilisée, que tu te poses des milliers de questions, parfois même que tu aies beaucoup de questions sans réponses !.. C'est aussi très normal tout ça !

Dis toi bien que ça sera pas toujours comme ça !....

Tu es juste en train de passer de la noirceur et aller vers la lumière !..

Tu es présentement dans un processus de transition... pour aboutir sur le chemin de la sagesse.... qui va te mener à bon port.

T'es belle, t'es fine, t'es capable...

Une femme avec beaucoup de courage, d'ambition, créative, intelligente, sociable, aimant les projets, joviale, autonome, remplie d'amour : tout ça c'est déjà là !

T'as pas à le demander, c'est déjà inné en toi !

D'accord! Lâche pas t'es capable!

Je t'aime! Tiens bon, bisou Xxx

\section{LETTRE À MA FILLE (Carlie)}

Quelle belle journée le jour que nos chemins se sont croisés, c'était vraiment par pur hasard, que le 15 septembre 2011 tu es apparue devant moi comme un ange qui venait de tomber du ciel. J'étais tellement souprise, figée. J'ai eu l'impression que mon cœur avait arrêté de battre. J'avais tellement peur que ce soit mon imagination qui n'allait pas bien. Mes jambes tremblaient tellement, que j'avais peur de tomber.

Et là, tu me demandes : «Es-tu Carlie ? ». Je te réponds : «Oui, tu es ma fille ». Je t’ai prise dans mes bras, et j'ai pleuré toutes les larmes de mon corps. J'avais peur de te lâcher, et que tu disparaisses. Après de longues minutes, j'ai fini par te lâcher, et tu m'as presenté mes petits enfants Cristelle 9 ans et Gille 4 ans, et ton tout petit bedon. Le $3 \mathrm{e}$ était dû dans presque 2 mois.

Les enfants était bouversés de me voir pleurer comme cela. Tu les a rassurés en leur disant : «C'est correct, c'est ma mère ». J'ai ressenti une très grande fierté quand tu as dit ce mot. (Et je me suis dit dans ma tête : peu inporte ce qu'il va arriver après cette 
rencontre. Elle me reconnait encore comme sa mère.) Là, on a échangé nos numéros de téléphone et puits tu m'as demandé du temps. Je t'ai respectée dans ta demande, mais j'ai trouvé le temps très long. Tous les jours je me demandais si tu allais m'appeler. J'avais tellement peur de ne pas te revoir. Et je me disais : "C'est vraiment le destin qui a fait qu'on se rencontre, alors pourquoi voudrait-il couper encore nos chemin ?»

J'ai fait confiance à la vie. 2 semaines après, c'est elle qui me texte en me demandant d'aller dîner au restaurant avec ses enfants et son ami. J'ai tout de suite dit oui. C'était pour la fête de Gille 4 ans. Moi, j'ai aimé dîner avec eux. Pour moi, c'était quelque chose qui commençait dans ma vie. J'avais peur qu'elle pense que j'allais trop vite. Après ce dîner, j'ai attendu son appel. C'était pour sa fête. Puis, elle disait qu'elle n'avait jamais vraiment eu de gâteau de fête. Alors, avec sa permission, on a fêté un souper de fête. C'était censé être moi, son ami et les enfants. En fin de compte, ses vrais amis étaient présents. J'étais tellement fière qu'elle me presente à ses amis. J'ai compris qu'elle me laissait rentrer dans sa vie. Quel beau cadeau qu'elle venait de me faire là.

Le temps passe. Elle me demande de garder : elle me faisait assez confiance. Après, les enfants ont commencé à m'appeler mamie. C'était tellement de grandes joies que je vivais. Je me disais que c'était impossible que la vie me donne de si belles choses. Et là, c'est ma fille qui me demande conseil. Elle me confie ses joies et ses peines, quand elle me demande conseil, je fais mon possible de lui répondre le mieux que je peux. Quand elle a seulement bessoin de parler, je l'écoute.

C'est sûr qu'on ne pourra jamais rattraper les longues années perdues. Mais aujourd'hui je sais qu'on peut avancer ensemble sur le très beau chemin que le destin nous a fait.

\section{LETTRE FICTIVE (Carlie)}

Ma fille Isabelle,

Merci de m'avoir fait une place dans ta vie et de m'avoir fait confiance. Tu es devenue une femme formidable avec tes 3 enfants. Vous êtes la famille que j'ai toujours rêvé d'avoir. Tu traverses très bien les épreuves que la vie te donne. Tu es une mère comme j'aurais aimé être avec toi. Ne doute jamais de toi. Tu es une maman et une fille merveilleuse.

De ta mère Carlie qui ne t'as jamais oubliée

\section{Textes libres de poésie et de prose}

ODE À MA MÈRE (Milana)

Se laver

À s'en gaver

S'endormir

Avec le sourire,

Moi, le nourisson

À peine sorti de ton cocon. 
Chouchouté, aimé

Dans la maternité

Enveloppante

Et caressante

De ton giron

Tout rond.

J'écoute scander le rythme

De nos cœurs à l'unisson

Quand nos biorythmes

Entonnent la même chanson.

Cela me rappelle

Notre union corporelle

Et même spirituelle

Lorsqu'en ton sein tu me portais.

Tu sais, j'écoutais et j'entendais

Tout ce que tu me disais !

Ces moments privilégiés,

Où nous n'étions que deux

À former ce duo bienheureux

Sont chers à mes yeux

Dans ce monde crépusculaire

Je respirais ton air,

Auréolée de ton amour

S'écoulaient ainsi mes jours

Avec toi, ma mère

ma lumière

Qui nourrit

ma vie.

« TOUT SE PASSE DANS LE VENTRE DE MA MÈRE » (Jackie)

« J'ai mal à ma mère !... »

Oh ! Oui j'ai mal à ma mère !...

C'est le trou noir de l'âme !..

Douleur, souffre-douleur !..

Je vis dans un ballon qui ressemble à une sphère !.

Je tourne en rond

Je n'aime pas l'atmosphère !.

Éternel mouvements de répétitions !..

Je me pose beaucoup de questions !..

J'ai mal à ma mère !...

elle est toujours là dans mon champ de vision!.

Est-ce que j'ai le mal imaginaire

Je l'entends, je la ressens,

Va au bout de ta formation, me dis-je !...

Peur de vivre, peur de mourir, 
J'ai rien pour me nourrir !..

Je suis en rémission !..

Toujours en opposition !..

J'ai mal à ma mère !..

Suis-je une fille ou un garçon !..

Bonne question !..

Ne va pas à l'encontre de ta décision

me dis-je encore une fois !..

Bon je coupe le cordon !..

Non c'est pas la bonne façon !..

J'étouffe, aucune respiration !..

Mais où sont mes poumons !..

Je dois aller jusqu'au bout de ma mission !..

Ah ! J'ai mal à ma mère !..

C'est toujours la même chanson !..

Chu pas près de la guérison !..

Je n'aime pas cette relation !..

Toujours dans l'indécision !..

Position alarme et inquiétante !..

Impossible d'exprimer mes émotions

Trop tôt, trop tard !..

Ais-je manqué le car !..

Est-ce que je pars ou je reste.

Bonne question !.. ce ne qu'une illusion !..

Trahison, humiliation, abandon, injustice, non désiré, non désirable, menaçante !.. et dérangeante !...

Cette nourriture pour moi !.. C'est que du poison !.. seul sujet de conversation !..

Je garde le silence !..

Incapable de reprendre confiance !..

Le mal de vivre, le mal de l'âme, le mal d'amour !.. le mal de mer !..

Tiens, je vais vomir ma mère !..

Réconciliation, pardon y'en est pas question !..

Ça viendra bien assez vite me dis-je !..

Par contre c'est peut-être ça la guérison!

Encore dans l'indiscussion!..

Toc!..Toc !..Toc !..on frappe à la porte !..

C'est mon jour de chance!..

C'est ma délivrance !..

Libération ! Libération ! Libération...

Sortir de cette sphère !..

Ce n'était que temporaire !..

Et ça recommence !..

Panique, nervosité, anxiété, hausse de pression !..

J'ai dû hériter ça de ma mère !..

Pas de fenêtre, pas de porte de sortie !..

Devrais-je sortir par son nombril !.. 
C'est une vraie comédie, me dis-je !..

Je ne parle pas, je ne vois pas, je ne marche pas !..

Zut !.. Alors je dois réfléchir !..

Pousse...Pousse....que j'entends !

Ah !.. c'est assez la violence !..

Entrons dans la danse !..

Ah ! Un peu de respect s.v.p.

Gardez-vous une petite gêne !..

Est-ce que ça rester dans mes gènes !

Ouf !... je suis sortie enfin!

Est-ce que c'est la fin !..

Libération! Libération!

Pas de discussion !..

J'entends une voix douce et rassurante !..

Mais j'ai mal dans mon ventre !..

Bienvenue dans le monde des adultes !..

J'entends, je ressens !..

C'est une voix différente, un odeur différente !..

Cherche-t-il à gagner ma confiance !..

Qui es-tu !.. Que veux-tu !..

Ta voix et ton odeur me sont inconnues !..

Qui es-tu !.. Que veux-tu !..

Des rêves brisés !.. un cœur brisé...

mes ailes sont brisées !..

Je ne peux plus m'envoler !..

Et cette voix me dit d'un calme rassuré :

Mon enfant vas-tu t'empêcher de respirer l'air parce que tu ne la vois pas !..

Vas-tu t'empêcher de croire en moi parce que tu ne me vois pas!

Femme de peu de foi, sors du coma!

Dépose tes deux pieds sur la terre ferme !.. toi la petite bohème...

N'ai pas peur, fais confiance il est là ton point d'ancrage !..

Courage courage me dis-je !..

Tu es un adulte maintenant !..

Tu dois vivre ton ici, et maintenant :

Maintenant ton lieu d'appartement est ici sur la planète Terre !.

Elle va devenir ta Mère nourricière !..

Sa fonction et sa mission sont !..

D'être à ton Service !.. et de voir à tous tes besoins :

Ne crains rien :

Te loger, te nourrir, te vêtir,

Sécurité, bien-être, confort, stabilité et encore et encore !..

Les 4 éléments dont tu pourras t'entourer : eau, feu, air, terre !..

Tout est là pour toi... en abondance tu dois y croire, et garder espoir d'accord !..

Oh !.. en passant !.. je veux te dire un petit secret !..

Lorsque t'es sortie de l'ombre pour venir dans la Lumière ! 
J'étais là pour t'accueillir moi et ton ange !.. et ont t'as chuchoté à l'oreille !.. on t'a souri et on t'a dit: on est fière que tu sois une petite fille...

Ton ami Jésus !.. 